'Inflammation Research

Center - VIB,

Rijvisschestraat 120

9052 Ghent, Belgium.

${ }^{2}$ Department of Biomedical

Molecular Biology - Ghent University, FSVM Building,

Technologiepark 927,

B-9052 Zwijnaarde,

Ghent, Belgium.

Correspondence to C.L.

e-mail:Claude.Libert@irc.

VIB-UGent.be

doi:10.1038/nrd4390

Published online

7 November 2014

\title{
Is there new hope for therapeutic matrix metalloproteinase inhibition?
}

\section{Roosmarijn E. Vandenbroucke ${ }^{1,2}$ and Claude Libert ${ }^{1,2}$}

Abstract | Matrix metalloproteinases (MMPs) are zinc-dependent endopeptidases that form a family of 24 members in mammals. Evidence of the pathological roles of MMPs in various diseases, combined with their druggability, has made them attractive therapeutic targets. Initial drug discovery efforts focused on the roles of MMPs in cancer progression, and more than $50 \mathrm{MMP}$ inhibitors have been investigated in clinical trials in various cancers. However, all of these trials failed. Reasons for failure include the lack of inhibitor specificity and insufficient knowledge about the complexity of the disease biology. MMPs are also known to be involved in several inflammatory processes, and there are new therapeutic opportunities for MMP inhibitors to treat such diseases. In this Review, we discuss the recent advances made in understanding the role of MMPs in inflammatory diseases and the therapeutic potential of MMP inhibition in those conditions.

Until approximately 15 years ago, matrix metalloproteinases (MMPs; also known as matrixins) were mainly known for their role in promoting cancer progression. Their ability to degrade connective tissue between cells and in the lining of blood vessels enables tumour cells to escape from their original location and seed metastases ${ }^{1}$. This knowledge prompted the development of the first generation of broad-spectrum synthetic inhibitors that block MMP activity by binding to the $\mathrm{Zn}^{2+}$ ion in their active sites. Preclinical studies using these inhibitors (such as batimistat (also known as BB-94)2) indicated that they had strong potential as anticancer agents ${ }^{1}$. Consequently, more than 50 MMP inhibitors were investigated in clinical trials. Surprisingly, despite the wealth of preclinical data supporting the use of MMP inhibitors as anticancer drugs, all of these trials failed. There are several explanations for these failures (BOX 1), including problems associated with the clinical trial itself (such as poor trial design and the use of inadequate clinical end points) and with the MMP inhibitors themselves (such as metabolic instability, poor oral bioavailability and dose-limiting toxicities). Moreover, poor knowledge of the complexity of MMP function and of the targeted MMPs, together with the use of broad-spectrum MMP inhibitors, resulted in some MMP agents inhibiting antitarget $\mathrm{MMPs}^{3-11}$.

While clinical trials with various MMP inhibitors were ongoing, new information regarding the role of MMPs was being uncovered, and the full story turned out to be more complex than previously thought. The idea that all MMPs promote the development of cancer was a misconception because not every MMP had been identified when the first clinical trials started. It subsequently became clear that not all MMPs need to be blocked in all cases and at all times ${ }^{12}$. Indeed, depending on their substrates, MMPs can have opposing effects on central aspects of tumour progression, such as tumour growth and survival, angiogenesis, invasion and modulation of the immune respons $\mathrm{e}^{13-15}$. In addition to their functions as tissue-remodelling enzymes, MMPs are also processing enzymes that selectively cleave many non-matrix targets, such as cell surface receptors, cytokines, chemokines, cell-cell adhesion molecules, clotting factors and other proteinases ${ }^{16}$.

Early clinical trials with broad-spectrum MMP inhibitors also revealed that prolonged treatment causes unwanted side effects, particularly musculoskeletal pain and inflammation ${ }^{17,18}$. These effects were reversible, but in subsequent trials the dose was reduced to avoid these inadvertent effects. Consequently, MMP inhibitor doses were often inadequate to affect tumour biology and combination therapies were never considered. Most worryingly, two trials involving the MMP inhibitor tanomastat in small-cell lung cancer and pancreatic cancer had to be halted prematurely as patients receiving the inhibitor showed significantly shorter survival than patients receiving placebo ${ }^{3}$. These undesired side effects were most probably due to the broad-spectrum inhibition of MMPs, as well as the cross-inhibition of a disintegrin and metalloproteinase (ADAM) family members 


\section{Box 1 Obstacles to the therapeutic use of MMP inhibitors}

Despite promising preclinical data supporting the blockade of matrix metalloproteinases (MMPs) as a treatment for cancer more than 10 years ago, all Phase III cancer trials failed owing to several reasons, as outlined below:

- The design of the clinical trials was suboptimal and inadequate clinical end points were used.

- The MMP inhibitors that were used were not ideal. Several were metabolically unstable, poorly orally bioavailable and/or associated with a dose-limiting toxicity. Moreover, early clinical trials with broad-spectrum MMP inhibitors revealed that prolonged treatment was associated with unwanted side effects and this resulted in the use of lower, often inadequate, MMP inhibitor doses in subsequent trials.

- At that time, there was poor knowledge on the complexity of MMP function and not every MMP had been identified. Consequently, inhibition of antitarget MMPs was not prevented and broad-spectrum MMP inhibitors were used, not taking into account time- and space-specific, and sometimes opposing, MMP functions. Indeed, the undesired side effects were most probably due to the broad-spectrum inhibition of MMPs, as well as the cross-inhibition of members of the a disintegrin and metalloproteinase (ADAM) family and aggrecanases (ADAMs with thrombospondin motifs (ADAMTS) family members).

- Finally, the discrepancies between the mouse models used in preclinical studies and the patients enrolled in the clinical trials likely contributed to the failure of the clinical trials. Indeed, patients were often in advanced stages of disease, whereas the animal studies had shown effectiveness of MMP inhibitors in early stages of disease.

Over the past two decades, the family of MMPs has been studied in more detail in several mammalian species, both at the gene and protein level, in health and disease. Many MMP-coding genes have been knocked out in mouse models, providing an in vivo system to investigate the consequences of the absence of these genes. Based on this research, MMPs are still regarded as important biological mediators that are detrimental in several diseases. It is intriguing why, despite their targetability, the development and marketing of specific MMP inhibitors has been delayed so much. Here, we summarize several possible reasons.

- The determinants of substrate specificity of MMPs are not well understood. Unlike other proteases, such as caspases, most MMPs have no obvious or strict consensus amino acid recognition sequence. This hampers the production of substrate-based inhibitors.

- There is uncertainty in translating in vitro substrate information to in vivo relevance. Incubating a biologically active MMP with another protein in vitro will often result in aspecific cleavage. However, this cleavage does not necessarily occur in an in vivo setting during health or disease.

- Many MMPs have evolved through gene duplication in the mammalian genome, leading to clusters of MMP genes on particular chromosomes (for example, the proximal mouse chromosome 9 harbours ten MMP genes in less than 500 kilobases) and to extensive homology in amino acid sequence. This impedes the development of specific MMP inhibitors and of reliable tools to detect specific MMP activity in vivo.

- MMP members have overlapping biological substrates, and therefore substrate-based inhibitors can rarely be specific.

- As most MMP-deficient mice do not show an obvious phenotypic abnormality in unstimulated conditions, except for MMP14- (REFS 299,300) and MMP20-deficient ${ }^{301,302}$ mice, not much has been invested in tissue-specific knockout mice. Consequently, there is insufficient knowledge on the spatiotemporal activities of MMPs in vivo during development, health and pathological conditions.

- The first clinical trial failures in the use of MMP inhibitors for cancer caused a shock wave in the MMP research community and beyond and made biotechnology and pharmaceutical companies reluctant to invest in newer generation MMP inhibitors.

- The high level of conservation of MMP genes in mammals indicates that they are essential for normal functioning of the organism. Hence, not all biological activities of MMPs are harmful, and although they could function as therapeutic targets in some conditions, they may be antitargets in other conditions.

and of aggrecanases (ADAMs with thrombospondin motifs (ADAMTS) family members). ADAMs and aggrecanases are considered to be involved in important cellular events, such as cellular adhesion, mediation of cell-matrix interactions, regulation of growth factor availability and membrane protein shedding ${ }^{19,20}$.

Another possible reason for the clinical trial failures is the lack of applicability of the mouse models to the patients enrolled in the clinical trials. That is, patients in the trials were often in advanced stages of disease, whereas in the animal studies MMP inhibitors in were effective in early stages of the disease.

Despite these disappointments, we and others think that inhibiting MMP activity is still a rational therapeutic approach, particularly for inflammatory disorders in which MMPs often activate or overactivate signal transduction pathways that control cytokine biosynthesis and direct systemic inflammation or barrier immunity ${ }^{21}$. In this Review, after describing the basic aspects of MMPs, their natural inhibitors and the advances made in optimizing the available MMP inhibitors, we provide an overview of the therapeutic potential of MMP inhibition in inflammatory diseases. We focus on systemic inflammatory response syndrome (SIRS), sepsis and disorders linked with intestinal and brain inflammation, discussing results from knockout and inhibitor studies in rodents. Finally, we reflect on the future prospects of developing therapeutic MMP inhibitors. 


\section{Basic aspects of MMP biology}

MMP activity was discovered in 1962 in tadpoles, in which a molecule with collagenolytic activity was shown to degrade extracellular matrix (ECM) proteins in the tails, which is a necessary process for metamorphosis ${ }^{22}$. MMPs belong to the metzincin superfamily of metalloproteinases (FIG. 1). MMPs are multidomain proteins with globular catalytic domains that are approximately 130-260 residues in length and have a common core architecture that is characterized by a long zinc-binding consensus motif, HEXXHXXGXX(H/D) and a methioninecontaining Met-turn. According to their structural characteristics, metzincins are primarily subdivided into astacins (including the meprins and bone morphogenetic protein 1 (BMP1) and/or Tolloids), adamlysins (including ADAMs and ADAMTSs), pappalysins, bacterial serralysins and $\mathrm{MMPs}^{23}$. The catalytic domain of all MMPs contains a $\mathrm{Zn}^{2+}$ ion that is coordinated by a tris(histidine) motif followed by a conserved methionine residue. So far, the MMP family comprises 24 structurally and functionally related members in mammals (FIG. 1; see Supplementary information S1 (table)).

MMPs typically have an amino-terminal signal peptide (pre-domain) to target the enzyme to the endoplasmic reticulum and transport it out of the cell. Next, there is a conserved pro-domain containing a consensus cysteine-switch sequence that shields the neighbouring catalytic domain, which contains a zinc-binding consensus sequence. At the carboxy-terminal end, most MMPs have a haemopexin-like domain that modulates substrate recognition and is connected to the catalytic domain by a flexible hinge region.

MMPs are synthesized as enzymatically inactive zymogens (pro-MMPs) that are activated by the 'cysteine switch, which disrupts the interaction between a cysteine in the pro-domain and the $\mathrm{Zn}^{2+}$ ion in the active site. Proteolytic removal of a bait region in the pro-domain by serine proteinases, furin or other MMPs destabilizes the pro-peptide and disrupts the $\mathrm{Zn}^{2+}$-cysteine interaction. Alternatively, the $\mathrm{Zn}^{2+}$-cysteine interaction can be disrupted through modification of the thiol group of the cysteine with physiological agents (for example, oxidants and disulphides) or non-physiological agents (for example, alkylating compounds and heavy metal ions), as well as through allosteric perturbation of the zymogen, which can lead to irreversible activation of the MMP by autolysis ${ }^{24}$.

The MMPs can be classified in different ways. The most commonly used classification is partly based on historical assessment of the substrate specificity of the MMP and partly based on the cellular localization of the MMP. According to these criteria, these groups are the collagenases, the gelatinases, the stromelysins and the membrane-type MMPs (MT-MMPs). However, several MMPs do not fit into any of these traditional groups.

Alternatively, MMPs can be classified on the basis of their domain organization as archetypal MMPs, matrilysins, gelatinases or furin-activatable $\mathrm{MMPs}^{25}$ (FIG. 1). Archetypal MMPs can be further subdivided into three subgroups on the basis of their substrate specificity: collagenases, stromelysins and 'other'. Collagenases (MMP1, MMP8, MMP13 and also MMP18 in Xenopus spp.) can process the collagen triple helix. Stromelysins (MMP3 and MMP10) have the same structural design as collagenases but cannot degrade native collagen, although they can activate several proMMPs. Four other archetypal MMPs (MMP12, MMP19, MMP20 and MMP27) cannot be classified as collagenases or stromelysins. There are only two matrilysins (MMP7 and MMP26), and these are characterized by the absence of a haemopexin domain. The gelatinases (MMP2 and MMP9) have a fibronectin type II motif located inside their catalytic domain, which enables them to bind and degrade gelatin (denatured collagen). As their name suggests, furin-activatable MMPs can be activated intracellularly by furin-like proteases owing to the furin recognition motif located between the propeptide and the catalytic domain. Three furin-activatable MMPs are secreted after activation: MMP11, MMP21 and MMP28. The other furin-activatable MMPs have membrane-anchoring domains that localize them at the cell surface, where they control the pericellular environment. They are anchored to the plasma membrane by a glycosylphospatidylinositol anchor (MMP17 (also known as MT4-MMP) and MMP25 (also known as MT6-MMP)) or by an extensive hydrophobic site in type I transmembrane MMPs (MMP14 (also known as MT1-MMP), MMP15 (also known as MT2-MMP), MMP16 (also known as MT3-MMP) and MMP24 (also known as MT5-MMP)). MMP23A and MMP23B (originally named MMP22) have unique features: they lack the conserved signal peptide, the cysteine-switch motif and the haemopexin domain, but they contain a cysteine array, an immunoglobulin domain and an $\mathrm{N}$-terminal type II transmembrane domain.

MMPs are important regulators of cellular activities. They collectively degrade structural components of the ECM and thereby influence several physiological processes, including reproduction, embryogenesis, angiogenesis and tissue remodelling; ECM degradation facilitates cell migration and the release of bound signalling molecules, such as chemokines, cytokines and growth factors ${ }^{26,27}$. In addition, it has become widely accepted that MMPs also have a central role in the direct activation of signalling molecules, such as tumour necrosis factor (TNF) and other cytokines; MMPs therefore also contribute to various aspects of immunity ${ }^{21,28}$. MMP activity is almost undetectable under normal physiological conditions but can be observed during certain biological processes such as angiogenesis, bone development, wound healing and mammary involution ${ }^{29}$. Owing to their destructive properties, they are tightly regulated at the levels of transcription, proteolytic activation of the zymogen, interaction with, and retention by, specific ECM components and inhibition by endogenous inhibitors, such as a 2 -macroglobulin and tissue inhibitors of metalloproteinases (TIMPs) ${ }^{30}$.

TIMPs are 21-28 kDa proteins that bind and reversibly block MMP activity ${ }^{21}$. Four TIMPs have been characterized and are either anchored to the ECM or secreted in a soluble form ${ }^{31,32}$. TIMPs consist of a C-terminal domain 


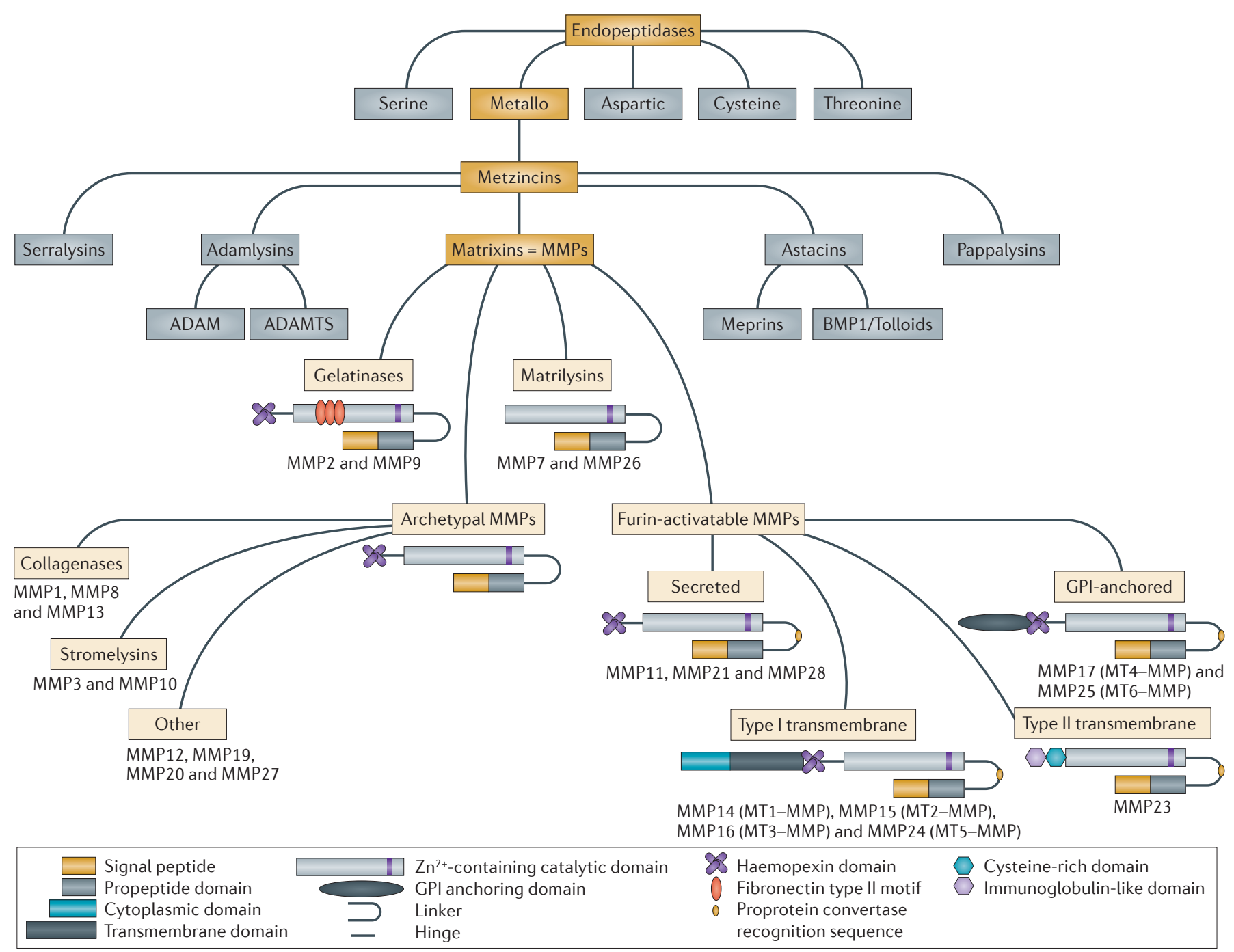

Figure 1 |Schematic overview of the structure of MMP family members and the relationship with other metzincin superfamily members. Matrix metalloproteinases (MMPs) share a common domain structure: the pre-domain that contains a signal peptide responsible for secretion; the pro-domain that keeps the enzyme inactive by an interaction between a cysteine residue and the $\mathrm{Zn}^{2+}$ ion group from the catalytic domain; and the haemopexin-like carboxy-terminal domain, which is linked to the catalytic domain by a flexible hinge region. MMP7 and MMP26 lack the hinge region and the haemopexin domain. MMP2 and MMP9 contain a fibronectin type II motif inserted into the catalytic site, and membrane-type MMPs (MT-MMPs) have a transmembrane domain or a glycosylphospatidylinositol (GPI) anchor at the $\mathrm{C}$ terminus. MMP23 has unique features: the amino-terminal signal anchor that targets MMP23 to the cell membrane, a cysteine array and an immunoglobulin-like domain. ADAM, a disintegrin and metalloproteinase; ADAMTS, ADAM with thrombospondin motifs; BMP1, bone morphogenetic protein 1.

and an $\mathrm{N}$-terminal domain that each contain three conserved disulphide bonds. The N-terminal domain folds within itself and binds to the active site of MMPs to inhibit their activity ${ }^{33}$. The TIMPs are highly similar in structure but have markedly different expression patterns; TIMP expression responds to various physiological stimuli in diverse cell types, comparable to MMP expression ${ }^{21}$. TIMP1, TIMP2 and TIMP3 are widely expressed in many mammalian tissues, whereas TIMP4 is expressed in specific tissues $^{34}$. TIMP1 is also expressed in specific regions of the brain, and TIMP3 is particularly expressed in the basement membranes of the eye and kidney ${ }^{34}$. TIMP4 expression is restricted to tissues such as the heart, kidney, ovary, pancreas, colon, testes, brain and adipose tissue $\mathrm{e}^{34}$. Although there is considerable overlap in the MMPs that they target, there is some specificity: TIMP2, TIMP3 and TIMP4 inhibit all MMPs, whereas TIMP1 inhibits all MMPs except MT1-MMP, MT2-MMP, MT3-MMP and MT5-MMP ${ }^{32}$. In addition, TIMP3 inhibits several ADAM and ADAMTS family members and TIMP1 inhibits ADAM10 (REF. 32). Mice deficient in TIMP1, TIMP2 or TIMP4 have no obvious abnormalities, whereas mice deficient in TIMP3 have lung emphysema-like alveolar damage, more rapid apoptosis of mammary epithelial cells after weaning, chronic hepatic inflammation and failure of liver regeneration ${ }^{35-37}$. 
Although there is a degree of substrate redundancy among MMPs, there is clearly an important selective pressure to conserve all MMP family members during mammalian evolution, which suggests that each MMP has specific and important functions. The availability of MMP-deficient mice has therefore been of great value in understanding their functions in several physiological processes and pathologies and in predicting the effects of potential inhibitors that target specific MMPs.

\section{MMP inhibitor development}

Hydroxamate-based inhibitors. Initial efforts to develop MMP inhibitors primarily focused on compounds containing a group that chelated the catalytic $\mathrm{Zn}^{2+}$ ion and a backbone designed to mimic the natural peptide substrate of the desired MMP or MMPs. The first-generation MMP inhibitors were based on the structure of collagen. These inhibitors comprised the basic backbone of collagen and the zinc-binding group hydroxamate $(-\mathrm{CONHOH})^{38}$, and they were consequently called hydroxamate-based MMP inhibitors (TABLE 1). Hydroxamate is a highly potent ligand that binds to the catalytic $\mathrm{Zn}^{2+}$ ion of the enzyme to create a distorted trigonal-bipyramidal geometry around the $\mathrm{Zn}^{2+}$ ion. In addition, the - $\mathrm{NH}$ group of the hydroxamate anion forms a short but strong hydrogen bond with the neighbouring carbonyl oxygen, and hydrophobic contacts stabilize the inhibitor-enzyme complex ${ }^{39}$. These strong $\mathrm{Zn}^{2+}$-chelating moieties reduce the contribution of the rest of the compound to the inhibitor-enzyme binding process, thereby favouring broad-spectrum inhibition ${ }^{6}$. Examples of collagen-based peptidomimetic hydroxamates include marimastat, ilomastat (also known as GM6001) and batimastat. Batimastat is a low-molecularmass hydroxamate derivative with low water solubility and was the first MMP inhibitor to enter clinical trials ${ }^{40}$. It inhibits several MMPs, including MMP1, MMP2, MMP7 and MMP9, by directly binding to $\mathrm{Zn}^{2+}$ ions in the active site $^{41}$. Several studies demonstrated promising antitumour effects of batimastat in animal models of human ovarian cancer xenografts, colorectal cancer, mouse melanoma and haemangioma ${ }^{42-47}$.

Several clinical studies of hydroxamate-based inhibitors were then conducted ${ }^{9,48,49}$, but the clinical performance of these compounds was disappointing. For example, marimastat was ineffective at doses already associated with musculoskeletal toxicity in a randomized Phase III trial for metastatic breast cancer that was stable or responding after first-line chemotherapy ${ }^{50}$. A Phase I trial of marimastat combined with carboplatin and paclitaxel as a therapy against advanced non-small cell lung cancer was also linked to musculoskeletal toxicity, but patients did have a partial response $\mathrm{e}^{51}$. Many factors contributed to the disappointing results, including the metabolically labile nature of the hydroxamate zinc-binding group and the serious side effects (such as musculoskeletal pain) experienced by patients taking these inhibitors. The musculoskeletal pain is now thought to be caused by the inhibition of non-MMP metalloproteinases, such as ADAM and ADAMTS family members, including ADAM17 (also known as TACE) ${ }^{52}$. In addition, hydroxamate-based inhibitors are broadspectrum inhibitors of many MMP subtypes, and at that time it became clear that MMPs affect many more than the five tumour-associated processes identified thus far (that is, metastasis, tumour growth, angiogenesis, apoptosis and immune modulation $)^{53}$. Unfortunately, this knowledge was not integrated into the ongoing clinical studies at that time. Moreover, it became clear that optimal clinical performance of the MMP inhibitors depended on administering the inhibitors during the critical MMP enzymatic event in the particular cancer, and this seemed to be early in the metastatic process ${ }^{48,53}$. Consequently, MMP inhibitors were often administered too late to make a difference ${ }^{54}$.

Subsequently, a new generation of hydroxamate-based MMP inhibitors was developed, and these consisted of a substituted aryl, a sulphonamide and a hydroxamate zinc-binding group. Examples include MMI-270, which is an orally available and water-soluble low-molecularmass broad-spectrum inhibitor ${ }^{55}$, and MMI-166, which is a selective inhibitor of MMP2, MMP9 and MMP14 (REF. 303). Other hydroxamate-based MMP inhibitors, such as ABT-770, PD-166793 and prinomastat, were developed to avoid binding to the 'shallow pocket' of MMP1, based on the idea, at that time, that MMP1-sparing inhibitors would not induce musculoskeletal toxicity ${ }^{56}$. Cipemastat (also known as Ro 32-3555), an MMP1, MMP3 and MMP9 inhibitor, was used for the treatment of rheumatoid and osteoarthritis, but its clinical trial was terminated prematurely because it did not prevent progression of joint damage in patients with rheumatoid arthritis ${ }^{57}$. In addition, a recurring limitation to these hydroxamates is that drug metabolism leads to the loss of the hydroxamate zinc-binding group.

Despite these disappointments, there is still interest in the design and development of hydroxamic acid derivatives, mainly because these compounds are the strongest available MMP inhibitors ${ }^{39}$. Indeed, new hydroxamate inhibitors are being developed using structure-activity relationship (SAR) analysis, which can help to identify molecular substructures related to the presence or absence of biological activity ${ }^{58}$. Moreover, quantitative SAR (QSAR) analysis is being used to predict the biological activity of new and untested compounds and even to forecast compounds from the knowledge of their molecular structures ${ }^{59}$.

Non-hydroxamate MMP inhibitors. Hydroxamic acids are often metabolically labile but there are several other zinc-binding groups that are stable. Reverse hydroxamates and non-hydroxamate inhibitors - for example, carboxylates, hydrocarboxylates, sulphydryls, phosphoric acid derivatives and hydantoins - were developed to avoid the limitations associated with the first-generation MMP inhibitors, such as metabolic inactivation and chelation of metals of other metalloproteins. In addition, once the structure of MMPs was revealed by crystallography, next-generation MMP inhibitors were no longer limited to substrate-like compounds, and new inhibitors were designed with various peptidomimetic and non-peptidomimetic backbone structures ${ }^{60}$. Numerous backbones were investigated, and they improved with increased knowledge of MMP structure and function. 
Rebimastat (also known as BMS-275291), which was one of the earliest non-hydroxamate MMP inhibitors developed, contains a thiol zinc-binding group and is a broad-spectrum MMP inhibitor. The structural scaffold of the thiol of rebimastat is a deep-pocket-binding, non-peptide mimetic and it was constructed to have sheddase-sparing activity, thus preventing inhibition of metalloproteinases that induce the release of TNF, TNF receptor 2, L-selectin, interleukin-1 (IL-1) receptor type 2, and IL-6 receptor ${ }^{61}$. However, a Phase II trial in earlystage breast cancer and a Phase III trial in non-small cell lung carcinoma both still revealed adverse effects ${ }^{62,63}$.

Tanomastat, which contains a thioether zinc-binding group and a biphenyl deep-pocket-binding segment, had good tolerance, but efficacy was variable and contradictory outcomes were obtained depending on the timing of administration ${ }^{64}$. The experience with tanomastat highlights the difficulties with respect to dosing and timing in relation to disease progression.

The thiol-based inhibitor SB-3CT contains a diphenylether deep-pocket-binding scaffold and is a competitive, mechanism-based inhibitor that is specific for MMP2 and MMP9 (REF 65). Mechanism-based MMP inhibitors bind to the active site of MMPs, resulting in a covalent enzyme modification. This strategy was also used to develop a mechanism-based inhibitor exclusively for MMP2 (REFS 66,67).

The orally bioavailable pyrimidine-based inhibitor Ro 28-2653 inhibits MT1-MMP (also known as MMP14), MT3-MMP (also known as MMP16), MMP2, MMP8 and MMP9 but spares MMP1 and ADAM17 activity ${ }^{5,68}$. Despite several promising animal studies that demonstrated antitumour and anti-angiogenic activity ${ }^{69-72}$, the inhibitor did not progress to clinical trials.

Potent MMP12 inhibitors and MMP13 inhibitors were developed when using the alternative zinc-binding group hydantoin ${ }^{73}$. In addition, several biphenyl sulphonamide carboxylate MMP inhibitors were designed for the treatment of osteoarthritis and have remarkable selectivity for MMP13 (REFS 74-76).

Phosphorous-based MMP inhibitors are structural mimics of the tetrahedral transition state of amide hydrolysis, in which the phosphinic group is the zinc-binding group ${ }^{77}$. Modulation of R1 and R2 substituents enabled optimization such that potency reached the nanomolar range ${ }^{77}$. This approach was particularly successful for the development of MMP13 phosphinates; for example, 582311-81-7 (REF. 78). Similarly, MMP11-selective phosphinate inhibitors, such as RXP-03, were developed; however, the efficacy of RXP-03 was dosedependent and treatment schedule-dependent ${ }^{79}$, which again highlights the importance of carefully defining the spatiotemporal function of the targeted MMP.

Tetracycline antibiotics, such as minocycline and doxycycline, have innate MMP inhibitory capacity. The tetracycline analogue doxycycline hyclate is indicated for periodontal disease and is the only collagenase inhibitor approved by the US Food and Drug Administration for any human disease ${ }^{80}$. The chemically modified tetracycline metastat (also known as COL-3) was tested in a Phase I clinical trial and induced disease stabilization in patients who had a nonepithelial type of malignancy ${ }^{81}$.

Targeting alternative binding sites. To avoid broad MMP inhibition owing to the high structural homology of the different MMPs and to reduce the off-target effects observed in clinical trials, recent research has switched from targeting the catalytic site to alternative, less conserved sites. Indeed, in addition to the $\mathrm{Zn}^{2+}$ ion in their catalytic site, MMPs possess subsites (S) designated as unprimed (left-hand side of the $\mathrm{Zn}^{2+}$ ion; S1, S2 and $\mathrm{S} 3$ ) or primed (right-hand side of the $\mathrm{Zn}^{2+}$ ion; $\mathrm{S1}^{\prime}, \mathrm{S}^{\prime}$ and $\left.\mathrm{S}^{\prime}\right)^{82}$ (FIG. 2). The $\mathrm{S}^{\prime}$ pocket is the main subsite for substrate recognition and is the most variable subsite among the different MMPs in terms of the amino acid sequence and the depth of the pocket. MMPs can be classified, on the basis of the depth of this pocket, into shallow, intermediate and deep-pocket $\mathrm{MMPs}^{60,83,84}$. The $\mathrm{P1}^{\prime}-\mathrm{S1}^{\prime}$ interaction (P1 is the group in the inhibitor or substrate that binds to the $\mathrm{S1}^{\prime}$ pocket of the enzyme) is the main determinant of the affinity of inhibitors and the cleavage position of peptide substrates ${ }^{85,86}$. For example, extending the $\mathrm{P} 1$ substituent was used to gain MMP13 selectivity over the highly homologous MMP2, taking advantage of the steric limitations of the shorter S1' loop of MMP2 (REF 74).

The use of X-ray crystallography and NMR methods combined with computational methods enables the modelling of drug-protein interactions with nonhydroxamate inhibitors of MMPs that bind to sites other than the catalytic site. This makes it possible to design compounds with greater potency and selectivity; indeed, inhibitors with up to three orders of magnitude stronger inhibition capacity of target MMPs compared with non-target MMPs have been developed ${ }^{6}$. Several of these inhibitors demonstrated impressive MMP13 selectivity, bind deep within the $S 1^{\prime}$ pocket and resulted in reduced clinical symptoms when tested in mouse models of rheumatoid arthritis and osteoarthritis ${ }^{87,88}$. Indeed, a co-crystal structure of a highly specific MMP13 inhibitor with the catalytic domain of MMP13 revealed a non-zinc binding mode that relies solely on interactions between the inhibitor and the $\mathrm{S} 1^{\prime}$ binding pocket ${ }^{89}$.

Similarly, an integrated computational and experimental approach that takes into consideration the structural differences of the $S 1^{\prime}$ pocket enabled improvement of selectivity in the inhibition of MMP2 over that of MMP9 (REF. 90). Analogues of a low-micromolar lead MMP13 inhibitor discovered through high-throughput screening were synthesized to investigate SARs, and this resulted in an MMP13 inhibitor that did not seem to bind to the S1' pocket but to exosites ${ }^{91}$. These exosites are located outside the substrate-binding pocket but are not yet identified.

It is still a challenge to identify alternative MMPspecific regulatory sites as they are often hidden and scattered over different locations on the surface of the protein. Combining structural spectroscopic analyses, NMR and protein crystallography with computational prediction of effector binding sites revealed these hidden sites, which can be exploited for the rational design of novel molecular effectors and therapeutic agents ${ }^{92}$. 


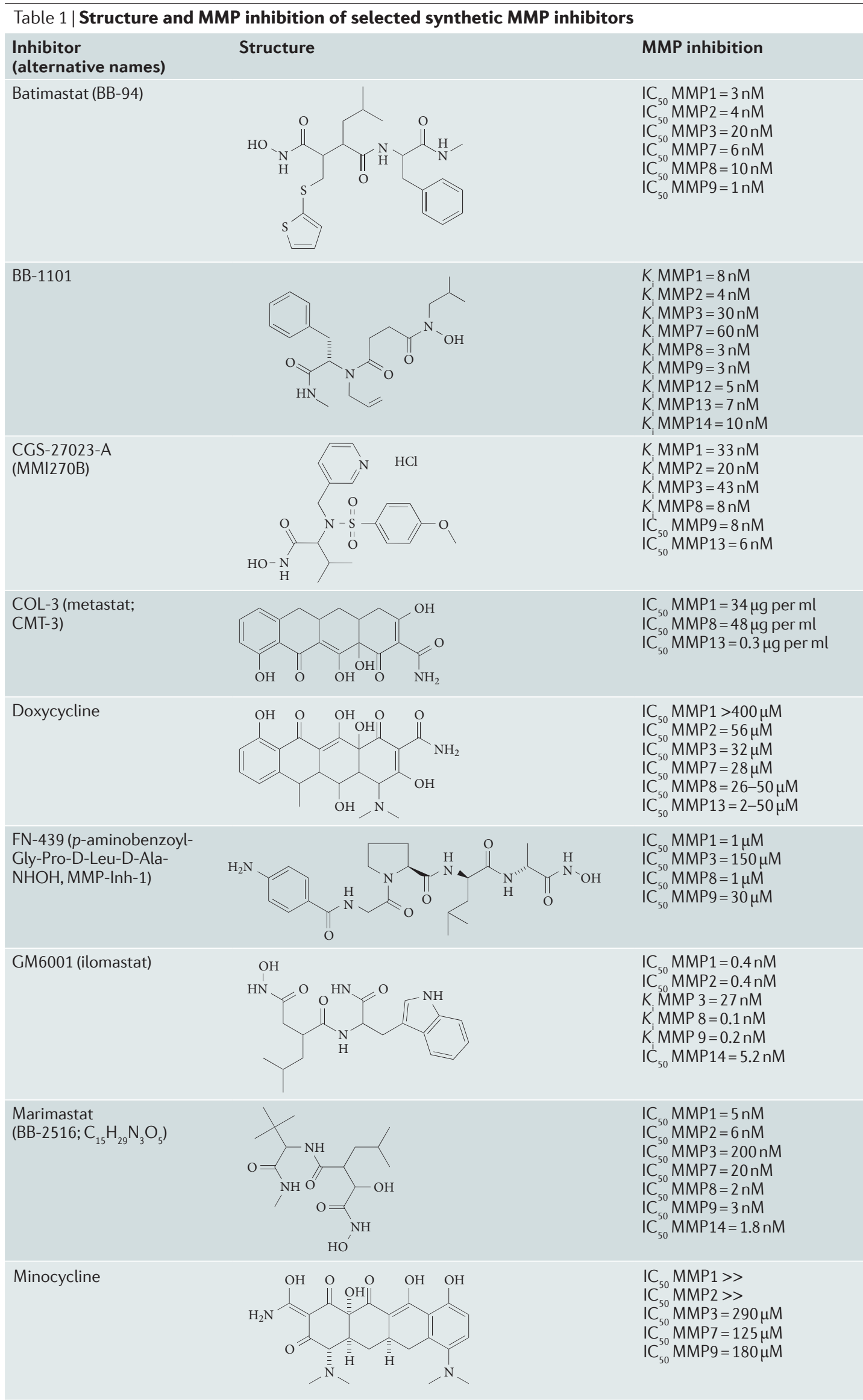




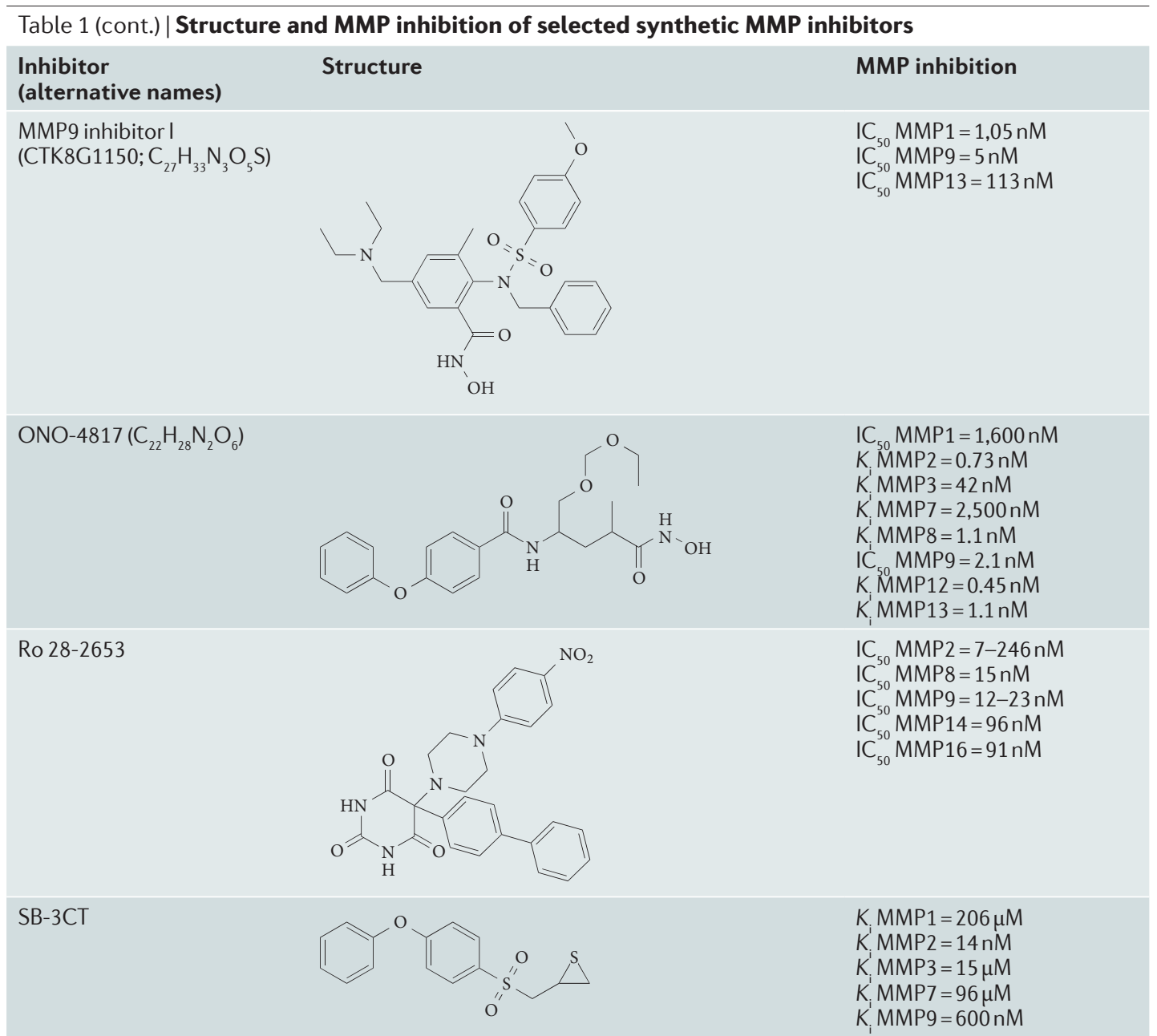

CMT, chemically modified tetracycline; $\mathrm{IC}_{50}$, half-maximal inhibitory concentration; $\mathrm{Ki}$, inhibition constant; MMP, matrix metalloproteinase.

Peptide-based MMP inhibitors often interact with secondary binding sites on MMPs and inhibitors have been designed that combine peptide-based inhibitors with conventional zinc-binding groups or alternatives ${ }^{93}$. Phage display peptide libraries have also been used to identify selective MMP2, MMP9 and MT1-MMP inhibitors that were effective in vivo ${ }^{94,95}$.

Antibody-based therapeutics. Recent research has also focused on the use of functional blocking antibodies, which have high selectivity and potency. Several functional blocking antibodies have been developed that selectively target the membrane-anchored MMPs ${ }^{96}$. Combining a human antibody phage display library with automated selection and screening strategies ${ }^{97}$ resulted in the identification of a highly selective antibody-based MMP14 inhibitor called DX-2400. DX-2400 displayed anti-invasive, antitumour and anti-angiogenic properties and blocked MMP14-dependent pro-MMP2 processing ${ }^{98}$.

Other groups developed selective MMP14 inhibitory antibodies that were successfully tested in vitro and in vivo ${ }^{99-101}$. The neutralizing monoclonal antibody REGA-3G12 was described as a selective inhibitor of MMP9 (REF. 102); REGA-3G12 is directed against the catalytic domain but not against the fibronectin or zincbinding domains ${ }^{103}$. Interestingly, the use of functional blocking antibodies often enables inhibition of specific functions of the MMP rather than its general proteolytic activity. For example, the mouse 9E8 monoclonal antibody targets only the MMP2-activating function of cellular MT1-MMP rather than the general proteolytic activity or the pro-migratory function of this $\mathrm{MMP}^{104}$.

Another proposed strategy for generating inhibitory antibodies that effectively target the in vivo activity of dysregulated metalloproteinases is mimicking the mechanism used by TIMPs ${ }^{105}$. Based on the three-dimensional structure and amino acid sequence of MMP13, a neutralizing antibody was developed that bound to the active form of MMP13 but not to the latent form or to other $\mathrm{MMPs}^{106}$. Another monoclonal antibody against MMP2 inhibited its activity but did not affect the closely related MMP9 (REF. 107); however, no other cross-reactivity was investigated with this antibody.

Endogenous inhibitors of MMP function. Several groups have focused on the use of endogenous MMP inhibitors as therapeutics, such as a2-macroglobulin and TIMPs ${ }^{34}$. a2-macroglobulin is a large serum protein that only 


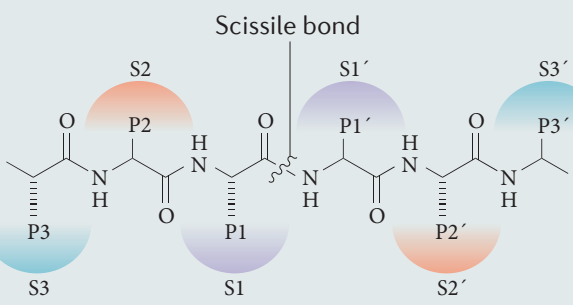

Figure 2 | Nomenclature of the substrate-protease interaction. Multiple enzymatic binding sites (P) directly contact the substrate-binding sites (S) of the substrate. The nomenclature of the $\mathrm{S}$ sites (for example S1-3 and $\left.\mathrm{S}^{\prime}-3^{\prime}\right)$ is concordant with the $\mathrm{P}$ sites ${ }^{82}$. Sn sites are amino-terminal to the scissile bond, and Sn' sites are carboxy-terminal to the scissile bond.

partly regulates MMP activity. MMPs are entrapped within the macroglobulin, thus preventing the MMP from accessing large substrates ${ }^{108}$. In addition, this complex is endocytosed and cleared by a low-density lipoprotein receptor-related protein ${ }^{109}$. Both chemically modified and polymyxin B-conjugated a2-macroglobulin demonstrated protective effects in mouse models of sepsis $^{110,111}$. However, this was linked to its binding to, and neutralization of, inflammatory cytokines and MMP inhibition was not studied.

Although TIMPs could theoretically form the basis of another novel class of MMP inhibitors, they have rarely been considered ${ }^{34}$ and it is unlikely that they will be used therapeutically. Until now, they have only been used in model systems to yield vital clues about the efficacy of metalloproteinase inhibitors in the abrogation of disease $^{112,113}$. In light of this, it is important to note that the idea that TIMPs only inhibit MMPs is a misconception, as several MMP-independent effects of TIMPs have been described ${ }^{114-116}$. For example, TIMP2 exerted anti-angiogenic effects via binding with integrin $\alpha 3 \beta 1$ (REFS 117,118). Moreover, domain-specific overexpression of TIMP2 and TIMP3 revealed MMP-independent functions of TIMPs during development ${ }^{119}$. It also seems extremely difficult to control the protease/antiprotease balance and, consequently, the net MMP activity. Moreover, in specific cases, TIMPs can even indirectly promote MMP activity ${ }^{120}$.

\section{MMPs in inflammatory diseases}

Despite the disappointing results from clinical trials of MMP inhibitors in oncology, there is increasing experimental evidence that selective MMP inhibition might lead to new therapies for inflammatory disorders ${ }^{121-127}$. MMPs are a crucial component of immune cell development and function, as has been reviewed in detail elsewhere ${ }^{21,128}$. Here, we discuss the recent advances achieved using MMP inhibitors and genetically modified mice in unravelling the roles of specific MMPs in inflammatory diseases such as sepsis and inflammation of the gut and brain. The importance of MMPs and MMP inhibition in lung diseases ${ }^{123}$, ischaemia-reperfusion ${ }^{124}$, periodontal inflammation ${ }^{80}$ and vascular pathologies ${ }^{125-127}$ has been recently reviewed elsewhere.
MMPs in SIRS and sepsis. Sepsis, severe sepsis and septic shock are escalating forms of SIRS initiated by an infection. According to recent estimates, the annual incidence of SIRS is $\sim 19$ million cases worldwide, but the actual number is probably much higher ${ }^{129}$. Overall, sepsis causes $\sim 20-30 \%$ mortality, which makes its treatment an urgent clinical need. Apart from antibiotics, the treatment of sepsis is mainly supportive care of organ functions. Many clinical trials of sepsis therapies have failed over the past decades, and the recent withdrawal of activated protein $\mathrm{C}$ from the market by Eli Lilly and Company ${ }^{130}$ and the decision to stop further clinical trials of CytoFab (AstraZeneca/BTG), which is a polyclonal TNF-specific antibody, illustrate the magnitude of the problem.

Treatment of sepsis is challenging owing to the complexity of the disease, which is at three levels: the patient (age, gender, genetic background, risk factors and other diseases); the microbial agent (bacteria, viruses and fungi); and the complexity of the host response. Regarding the host response, patients with SIRS clearly show both an inflammatory and an immune-suppressive profile. Hence, it is not always clear whether inflammation should be blocked or immune suppression should be reverted as patients need an immune response to deal with the infection ${ }^{129}$. Therefore, partial or local inhibition of inflammatory mediators or pathways may decrease inflammation while maintaining an appropriate level of immune activation, as was recently shown by using very low dose glucocorticoids in a mouse model ${ }^{131}$.

Apart from inflammation, other complex processes are also activated during sepsis, such as the complement system, coagulation and fibrinolysis. Furthermore, the failure of clinical trials should be interpreted in the light of the substantial differences in genomic responses in leukocytes (one of many important immune cell types) between humans and mice, indicating that mice are suboptimal for preclinical studies of sepsis ${ }^{132}$. There are many arguments against this point of view, but the discussion illustrates a strong concern that our current models cannot accurately predict the outcome of new investigative therapies.

Several mouse models of sepsis are used in studies, such as endotoxaemia (a form of septic shock caused by the injection of bacterial lipopolysaccharides), kidney ischaemia-reperfusion, and cecal ligation and puncture (CLP). Of all of these models, CLP is recognized as the gold standard mouse sepsis model, in which live bacteria stimulate the host via several pathways, including endotoxins released by the bacteria ${ }^{133}$. Injection of high doses of bacteria into mice is not a valid sepsis model for MMP research as bacterial proteases might activate $\mathrm{MMPs}^{134}$, so the data from these experiments could be misleading.

Our current understanding of sepsis suggests that development of successful therapeutic strategies must address the activation of multiple pathways during sepsis (inflammation, coagulation, fibrinolysis and complement) ${ }^{129}$. Notably, sepsis treatment is short-term, and so the toxicity profiles of these drugs do not have to be as 'clean' as they do for long-term treatments. Interestingly, 
several MMPs are simultaneously biologically active in several of these multiple pathways, making MMPs interesting therapeutic candidates for sepsis treatment ${ }^{122}$ (FIG. 3).

It has long been known that the expression of many MMP family members is enhanced in endotoxaemia ${ }^{135-137}$, and studies using MMP inhibitors and MMP-knockout mice indicate that MMPs have essential roles in infection and in host defence ${ }^{138,139}$ (TABLE 2). Broad-spectrum MMP inhibition by GM6001 decreased CLP-induced neutrophil expression of macrophage receptor 1 (MAC1; also known as integrin $\alpha \mathrm{M}$ ), the production of CXC chemokines, oedema and neutrophil infiltration in the lung ${ }^{140}$. Similarly, in CLPinduced septic rats, the chemically modified tetracycline
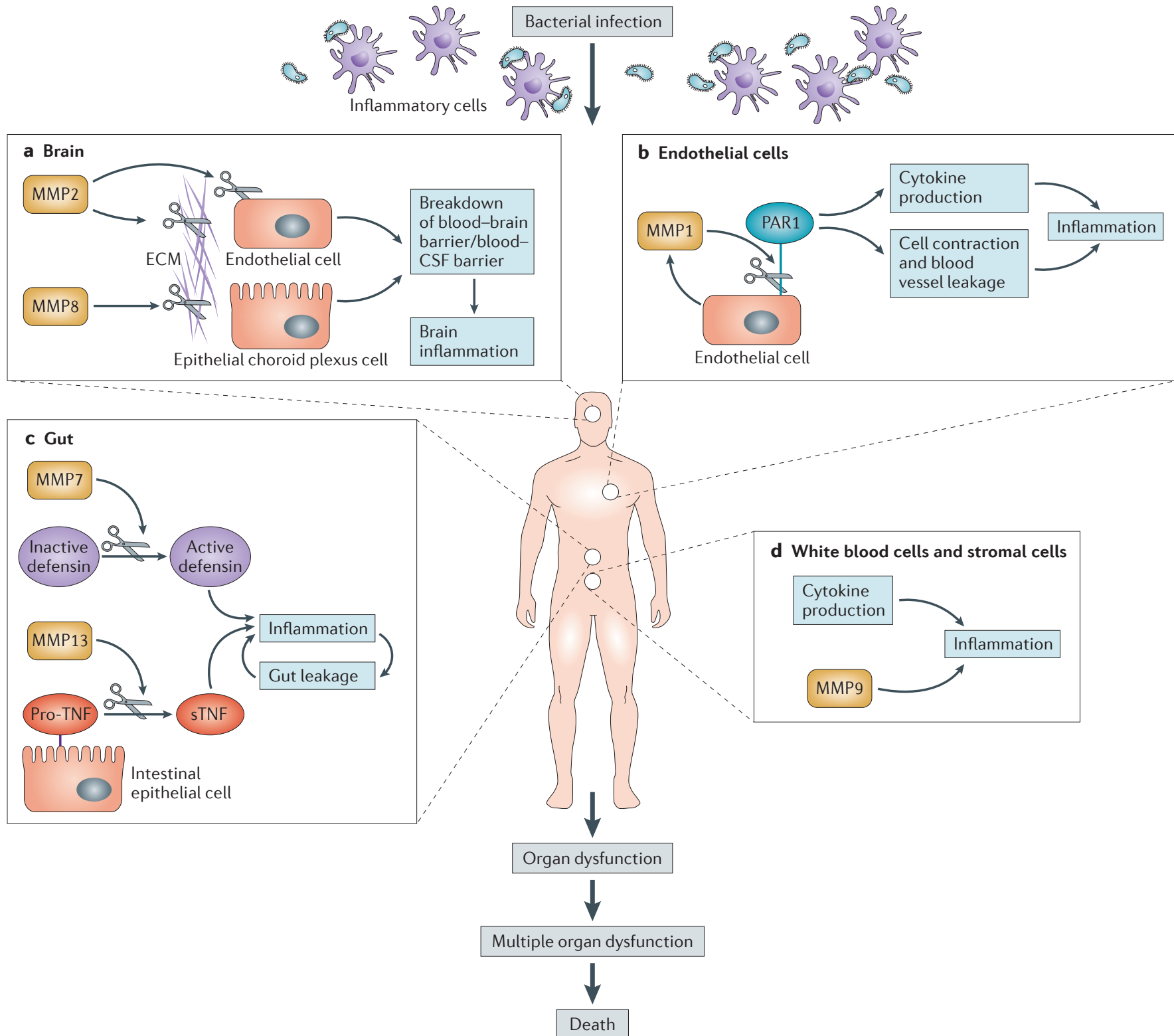

Figure 3 | Overview of the most important MMPs in sepsis. Sepsis is a systemic inflammatory response to infection and is associated with a high mortality rate. Although several complex systems are activated in sepsis (such as coagulation, fibrinolysis and complement), the disease is clearly inflammatory in nature, at least in the initial phase. Subsequent immune suppression may complicate the disease. Inflammation is driven by cytokines, but matrix metalloproteinases (MMPs) also have a detrimental role. Inflammation leads to direct cellular damage, which, together with hypoperfusion of the organs owing to a drop in blood pressure, leads to lethal organ damage. a| MMP2 particularly affects the brain endothelium of the blood-brain barrier (BBB), leading to disruption of the BBB and brain inflammation. MMP8 also compromises the brain barrier, namely the epithelial choroid plexus between blood and cerebrospinal fluid. MMP8 degrades collagen and cells lose their shape, leading to a disruption of the barrier and spread of the inflammation to the brain. $\mathbf{b}$ | MMP1 is induced in vascular endothelial cells and activates the procoagulant, inflammatory and cell integrity-disrupting protease-activated receptor 1 (PAR1). c| MMP7 stimulates inflammation in intestinal epithelial cells by activating pro-inflammatory defensins, whereas MMP13 stimulates intestinal epithelial cell by cleaving membrane-bound pro-tumour necrosis factor (pro-TNF) to soluble TNF (sTNF). d | Infection results in the activation of both white blood cells and stromal cells that produce cytokines and MMPs, such as MMP9. This further enhances systemic inflammation. CSF, cerebrospinal fluid. 
COL-3 (which is a broad-spectrum MMP inhibitor) had reduced toxicity and a reduced ability to cross the bloodbrain barrier $(\mathrm{BBB})^{141,142}$, which led to reduced sepsisinduced lung injury and improved survival ${ }^{143}$.

Many researchers initially focused on MMP9 as a therapeutic target ${ }^{144}$, as its expression is increased in patients with septic shock ${ }^{145}$ as well as in animal models of endotoxaemia and CLP-induced sepsis ${ }^{146}$. MMP9-deficient mice were protected against lipopolysaccharide-induced lethality ${ }^{137}$, and use of an MMP9 chemical inhibitor that also inhibits MMP8 and ADAM17 confirmed the protective effect of MMP9 inhibition in endotoxaemia ${ }^{147}$. In the CLP-induced sepsis model, MMP9-deficient mice were hypersensitive to CLP-induced sepsis ${ }^{148}$; however, MMP9 inhibition in rats protected them from CLP-induced BBB dysfunction ${ }^{149}$. These results illustrate that the endotoxaemia model may not be a suitable model to evaluate sepsis therapeutics as it is fundamentally a model of acute inflammation and lacks the contribution of living bacteria. Moreover, these data also highlight the different outcomes from studies using knockout mice (which lack the gene, the function of which can be compensated by other gene products) compared with studies using inhibitors (which may lack specificity and sufficient bioavailability). Indeed, the endotoxin model does not adequately mimic clinical sepsis as it lacks an infectious source from which bacteria invade the host and cause SIRS. Additionally, this research illustrates that in sepsis, certain MMPs may be antitargets rather than therapeutic targets.

Over the past 3 years, promising breakthroughs have been achieved and the roles of a few MMPs in mouse sepsis models have been discovered. In 2011, Tressel et al. ${ }^{150}$ reported that circulating levels of MMP1 (also known as collagenase 1) are increased in patients with sepsis and that higher levels of active MMP1 directly correlate with lower rates of survival in these patients. In the CLP-induced sepsis model, MMP1A was released from endothelial cells and detected in the circulation shortly after onset of inflammation. A chemical MMP inhibitor that blocks MMP1 and MMP8 protected mice from CLP-induced lethality, and protection was also obtained using an MMP1-specific antibody. The mechanism by which MMP1 contributes to sepsis is thought to be at the level of coagulation as it was observed that MMP1 is the protein that is primarily responsible for the activation of protease-activated receptor 1 (PAR1), an endothelial transmembrane protein that is responsive to the clotting protease thrombin. Interestingly, PAR1 is also the therapeutic target of activated protein C. Cleavage of PAR1 leads to inflammation and endothelial dysfunction, which is a hallmark of sepsis ${ }^{151}$. Although therapeutic MMP1 inhibition protected wild-type mice from CLPinduced lethality and reduced lung vascular permeability, clotting abnormalities and cytokine production, it did not protect PAR1-deficient mice from CLP-induced lethality, which suggests that the activities of MMP1 are strictly PAR1-mediated ${ }^{152}$. However, PAR1-deficient mice were not resistant to CLP-induced lethality and survival rates became significantly worse when the MMP1 inhibitor was administered in the advanced stage of disease, suggesting that MMP1 (and hence PAR1) inhibition at later stages is not desirable. Notably, MMP1A-deficient mice do not show any abnormalities ${ }^{153}$, but MMP1 is one of the MMPs implicated in the MMP inhibitor-associated musculoskeletal pain syndrome. It would therefore be interesting to test whether treatment with an MMP1-specific antibody induces musculoskeletal pain.

A second MMP that has therapeutic potential in sepsis is MMP8 (also known as collagenase 2), which is expressed by many cell types and has several potential substrates ${ }^{154,155}$. In 2007, Tester et al. ${ }^{156}$ reported that MMP8-deficient mice did not mount an inflammatory response in a model of local lipopolysaccharide-induced inflammation; MMP8 normally activates an inflammatory chemokine called LIX. Interestingly, two groups described a direct association between MMP8 serum levels and mortality in sepsis patients ${ }^{157,158}$. It has been proposed that MMP8 could be a potential biomarker for sepsis, to be used alongside MMP1 and the previously reported MMPs, MMP3 (REF. 159), MMP9 and MMP10 (REF. 160). Moreover, the crucial role for MMP8 in sepsis indicated by these results was confirmed in studies demonstrating that MMP8-deficient mice were resistant to different types of induced sepsis. Solan et al. ${ }^{158}$ induced sepsis via CLP in MMP8-deficient mice and presented arguments for activation of nuclear factor $-\kappa \mathrm{B}(\mathrm{NF}-\kappa \mathrm{B})$ by MMP8 (REF. 158). Consistent with these results, we found that MMP8-deficient mice were highly resistant to the lethal effects of endotoxaemia, CLP and kidney ischaemia-reperfusion and that an MMP8 chemical inhibitor elicited similar effects ${ }^{161}$. We linked this resistance to MMP8-dependent collagen degradation that causes increased leakage of the blood-cerebrospinal fluid barrier (a single layer of choroid plexus epithelial cells that forms a tight barrier between the blood and the brain $)^{161}$. However, not all groups have found reduced inflammatory responses to endotoxin in MMP8-deficient mice; for example, in one study, MMP8 deficiency promoted a lung inflammatory response during endotoxaemia via the modulation of S100A8 and S100A9 (REF. 162). This result provides a reminder that endotoxaemia and sepsis are the consequences of complex host responses involving pathways that may be stimulated or inhibited by a given MMP.

Another MMP that has recently been recognized as important in sepsis is MMP13 (also known as collagenase 3), which has been extensively investigated in several inflammatory conditions, particularly arthritis ${ }^{163}$ and wound healing ${ }^{164}$. This resulted in the development of selective MMP13 inhibitors ${ }^{165}$. MMP13 transcription is increased in response to inflammation through $\mathrm{NF}-\kappa \mathrm{B}$ and mitogen-activated protein kinase (MAPK)regulated elements in its promoter ${ }^{166,167}$. However, antiinflammatory glucocorticoids also increase MMP13 transcription in a manner that is dependent on the activator protein 1 binding site in the MMP13 promoter $^{168}$. We have shown that MMP13-deficient mice were resistant to endotoxaemia and CLP-induced sepsis ${ }^{169}$. These data are consistent with the idea that the gut is the driving force in sepsis and that MMP13 controls sepsispromoting factors in the gut ${ }^{170,171}$. This hypothesis states that the gut epithelium, which is one-cell-layer thick 


\begin{tabular}{|c|c|c|c|}
\hline $\begin{array}{l}\text { Mmp } \\
\text { inhibitor }\end{array}$ & Species & Observations & Refs \\
\hline \multicolumn{4}{|c|}{ CLP-induced sepsis } \\
\hline GM6001* & Mouse & $\begin{array}{l}\text { Reduced CLP-induced neutrophil infiltration, CXC chemokines and } \\
\text { oedema in the lungs }\end{array}$ & 140 \\
\hline $\mathrm{COL}-3^{*}$ & Rat & $\begin{array}{l}\text { Reduced pulmonary injury and improved survival in a dose-dependent } \\
\text { manner }\end{array}$ & 143 \\
\hline $\begin{array}{l}\text { MMP9 inhibitor } \\
\mathrm{C}_{27} \mathrm{H}_{33} \mathrm{~N}_{3} \mathrm{O}_{5} \mathrm{~S}^{*}\end{array}$ & Rat & Reduced BBB dysfunction & 149 \\
\hline FN-439* & Mouse & $\begin{array}{l}\text { Reduced disseminated intravascular coagulation and markedly } \\
\text { suppressed pro-inflammatory cytokine response owing to PAR1 cleavage }\end{array}$ & 150,152 \\
\hline MMP2 inhibitor & Rat & Reduced BBB dysfunction & 149 \\
\hline $\begin{array}{l}\text { Mmp } 8^{-1-}, \text { MMP8 } \\
\text { inhibitor }\end{array}$ & Mouse & Improved survival and induced a blunted inflammatory profile & 158 \\
\hline$M m p 8^{-/-}$ & Mouse & Improved survival & 161 \\
\hline Mmp13 $13^{-/-}$ & Mouse & Improved survival & 169 \\
\hline \multicolumn{4}{|l|}{ Endotoxaemia } \\
\hline$M m p 9^{-/-}$ & Mouse & Reduced lethality & 137 \\
\hline Regasepin $1^{\S}$ & Mouse & Reduced lethality & 147 \\
\hline $\mathrm{Mmp}^{-1-}$ & Mouse & Exacerbated lung inflammatory response & 162 \\
\hline$M m p 7^{-/-}$ & Mouse & Improved survival and reduced intestinal damage & 178 \\
\hline $\begin{array}{l}\text { Mmp } 8^{-/-} \text {and } \\
\text { MMP8 inhibitorll }\end{array}$ & Mouse & Improved survival and reduced blood-CSF barrier leakage & 161 \\
\hline Mmp13 $13^{-/-}$ & Mouse & Improved survival and reduced intestinal damage & 169 \\
\hline \multicolumn{4}{|c|}{ kidney ischaemia-reperfusion } \\
\hline $\mathrm{Mmp}^{-/-}$ & Mouse & Improved survival & 161 \\
\hline \multicolumn{4}{|c|}{ Intraperitoneal infection with Escherichia coli } \\
\hline $\mathrm{Mmp9}^{-/-}$ & Mouse & $\begin{array}{l}\text { Enhanced bacterial outgrowth in the peritoneal cavity, increased } \\
\text { dissemination of the infection, diminished recruitment of leukocytes } \\
\text { to the site of infection and enhanced severe distant organ damage } \\
\text { during infection }\end{array}$ & 148 \\
\hline
\end{tabular}

BBB, blood-brain barrier; CLP, cecal ligation and puncture; CSF, cerebrospinal fluid; MMP, matrix metalloproteinase; PAR1, protease-activated receptor $1 .{ }^{*}$ These structures are shown in TABLE 1. ${ }^{\ddagger}((3 R)-(+)-[2-(4-m e t h o x y b e n z e n e s u l p h o n y l)-1,2,3,4-$ tetrahydroisoquinolone-3-hydroxamate]). ${ }^{\S}$ Peptidomimetic gelatinase B inhibitor. " $\alpha$-biphenylsulphonylamino-2-methylpropyl phosphonate.

and covered on the luminal side by a mucus layer that prevents direct contact with microorganisms from the gut, forms an important barrier that becomes permeable in sepsis. This permeability leads to life-threatening traffic of gut microbiota, pathogen-associated molecular patterns and danger-associated molecular patterns into the blood and the subsequent amplification of systemic inflammation in sepsis. Local expression of the cytokine TNF has been shown to be involved in the loss of gut barrier function, and hence this local TNF can be considered as a factor that amplifies a local effect to a systemic scale. TNF is first expressed as a transmembrane protein, which is cleaved and released as the mature $17 \mathrm{kDa}$ form by ADAM17. Several MMP members can cleave and release TNF ${ }^{169,172-175}$. The protection of MMP13-deficient mice in sepsis was specifically accompanied by reduced TNF release, and we identified several MMP13 cleavage sites in the pro-TNF protein ${ }^{169}$. These findings suggest that MMP13 that is expressed locally in the gut activates TNF in an ADAM17-independent manner, which leads to gut permeability ${ }^{176}$.
It is interesting to note that the three prominent MMPs that seem to have a central role in sepsis, according to studies using MMP-deficient mice and inhibitors, are the collagenases: MMP1, MMP7 and MMP13. This could be a coincidence, as the substrates of these MMPs are markedly different; however, the coincidence could also be due to the strong evolutionary relationship between these three MMPs ${ }^{177}$. The genes that encode MMP1, MMP8 and MMP13 are located in one cluster on proximal chromosome 9 in the mouse ${ }^{25}$. The three MMPs have diverse substrates but all target cells that are involved in sepsis, namely endothelium, choroid plexus and gut epithelium; therefore, a chemical inhibitor of all three MMPs might be a useful therapeutic to prevent the onset and progression of sepsis by inhibiting its progression at multiple stages. Agents that simultaneously inhibit MMP1, MMP8 and MMP13 do not exist yet, but MMP13 blockers with substantial MMP8 inhibitory potential have been described and could provide lead compounds to develop such triple inhibitors. Although a single inhibitor that can inhibit all of these targets 
might be difficult to develop, as their active sites and S1 and S1' pockets differ substantially, combining MMP8and MMP13-selective inhibitors could be promising in the treatment of sepsis.

Other MMPs have been recently shown to have a role in mouse models of sepsis. We reported that MMP7 deficiency is protective in endotoxaemia (owing to the reduction in $\alpha$-defensin activation and the subsequent reduction in stimulation of IL- 6 release by macrophages $)^{178}$. It is important to note that the mechanism of enteric $\alpha$-defensin activation in humans differs from that in mice and is MMP7-independent. This therefore excludes MMP7 as a potential therapeutic target to treat sepsis. MMP2 levels were increased in patients with sepsis and this was associated with decreased survival ${ }^{179}$. In addition, MMP2 inhibition reversed sepsis-induced $\mathrm{BBB}$ permeability and reduced brain inflammation and oxidative damage in an animal model of sepsis ${ }^{149}$. However, there are no reports showing whether MMP2 deficiency or inhibition is correlated with better overall outcome in mouse models of sepsis.

MMPs in intestinal inflammation. The functional integrity of the gut barrier is crucial for intestinal immune homeostasis. Damage to the epithelium triggers inflammatory responses owing to bacterial antigens that enter the lamina propria ${ }^{180}$. Proteolytic enzymes such as MMPs are secreted by both resident and infiltrating cell types and modulate the intestinal barrier function ${ }^{181}$. Consequently, MMPs are involved in the pathophysiology of several intestinal inflammatory disorders, including inflammatory bowel disease (IBD), necrotizing enterocolitis (NEC), collagenous colitis and diverticulitis $^{182}$. Inhibitor and knockout studies indicate that some of these MMPs might have therapeutic potential (FIG. 4; TABLE 3).

IBD, which is an umbrella term that includes Crohn's disease and ulcerative colitis, results from both dysregulated genetic factors and environmental factors. A combination of commensal microbiota and aberrations in epithelial cells and the immune system contribute to IBD progression $^{183}$. The use of 2,4,6-trinitrobenzenesulphonic acid (TNBS) or dextran sulphate sodium (DSS) to induce colitis in mice or rats are two valuable IBD models for gaining a better understanding of acute inflammatory processes in IBD.

Although TNF antagonists are often successfully used to treat $\mathrm{IBD}^{184}$, not all patients respond to these drugs and could therefore benefit from alternative treatments ${ }^{185}$, which might include MMP inhibitors. Indeed, data from both mice and human studies suggest that MMPs have a detrimental role in IBD. Although additional studies are needed, one study revealed that single nucleotide polymorphisms in MMP3, MMP8, MMP10 and MMP14 are significantly associated with an increased risk of developing ulcerative colitis ${ }^{186}$. Furthermore, treatment with the broad-spectrum MMP inhibitors batimastat or marimastat ameliorated the inflammatory alterations in TNBS-induced colitis in rats ${ }^{187,188}$. Similarly, AE-941, which is a natural inhibitor of MMPs that is derived from shark cartilage ${ }^{189,190}$, administered by gastric lavage in a rat model of ulcerative colitis, had therapeutic effects ${ }^{191}$. Also, minocycline (a semisynthetic tetracycline that inhibits MMPs) protected mice from DSS- and TNBSinduced colitis ${ }^{192}$, whereas ilomastat (a broad-spectrum MMP inhibitor) protected rats from TNBS-induced ulcerative colitis ${ }^{193}$. The orally active MMP inhibitor ONO-4817 (TABLE 1), which inhibits MMP2, MMP3, MMP8, MMP9, MMP12 and MMP13 but not MMP1 and MMP7, reduced DSS-induced inflammatory cell infiltration and mucosal cell disruption ${ }^{194}$. However, the synthetic MMP inhibitor CGS-27023-A did not influence mucosal repair in a rat model of DSS-induced colitis despite the significant decrease in extent and severity of epithelial injury ${ }^{195}$. Collectively, these studies support the hypothesis that MMP inhibition is an attractive and promising strategy for treating IBD and that these inhibitors have therapeutic potential. Selective targeting of the pathological MMPs is probably a more clinically appropriate approach to avoid the undesirable side effects that are associated with broad-spectrum MMP inhibition.

Only a few studies have addressed the role of single MMPs in the pathology of IBD. MMP13 gene expression was significantly increased in the colonic mucosa of patients affected by ulcerative colitis ${ }^{196}$. We have shown that the absence of MMP13 is slightly protective in a model of DSS-induced colitis, and we attributed this to MMP13-dependent cleavage of pro-TNF into bioactive $\mathrm{TNF}^{169}$. Epithelial-derived MMP9 is absent in normal colonic tissue but is upregulated in both the serum and tissue of patients with IBD, and this upregulation is associated with higher disease activity ${ }^{197-199}$.

Apart from the use of MMP9 as a biomarker for IBD, several animal studies revealed that MMP9 also drives colitis, making it an interesting therapeutic target for $\mathrm{IBD}^{200-204}$. Both prophylactic and therapeutic treatment of mice with antibodies that block MMP9 function substantially attenuated the severity of DSS-induced colitis $^{105}$. By contrast, MMP2, another gelatinase that has structurally similar active sites and substrates to MMP9, protected against the development of colitis ${ }^{205}$. However, the absence of both MMP9 and MMP2 in colitis showed that MMP9-mediated tissue injury overrides the protective effect of MMP2 during colitis. This suggests that treatment of colitis by inhibiting MMP9 might be beneficial even if it also inhibits MMP2 (REF. 206).

MMP8 also seems to have a role in IBD, as suggested by the increased MMP8 levels in patients with IBD and in mice with DSS-induced colitis ${ }^{199}$. Increased mucosal and plasma levels of MMP1 were correlated with the presence of ulcerative colitis in patients ${ }^{207-209}$. MMP1 promoted secretion of TNF in a positive feedback manner to cause further injury in the colon mucosa ${ }^{210}$. However, no studies are available on therapeutic MMP1 inhibition. Another MMP that is often suggested to have a detrimental role in IBD is MMP3. Plasma cells from patients with Crohn's disease and ulcerative colitis expressed significantly higher levels of MMP3 protein and transcripts than controls ${ }^{211}$, and this was also reflected in mucosal tissue and correlated with morphological damage ${ }^{212}$. Additionally, lamina propria myofibroblast-derived MMP3 activated neutrophil 


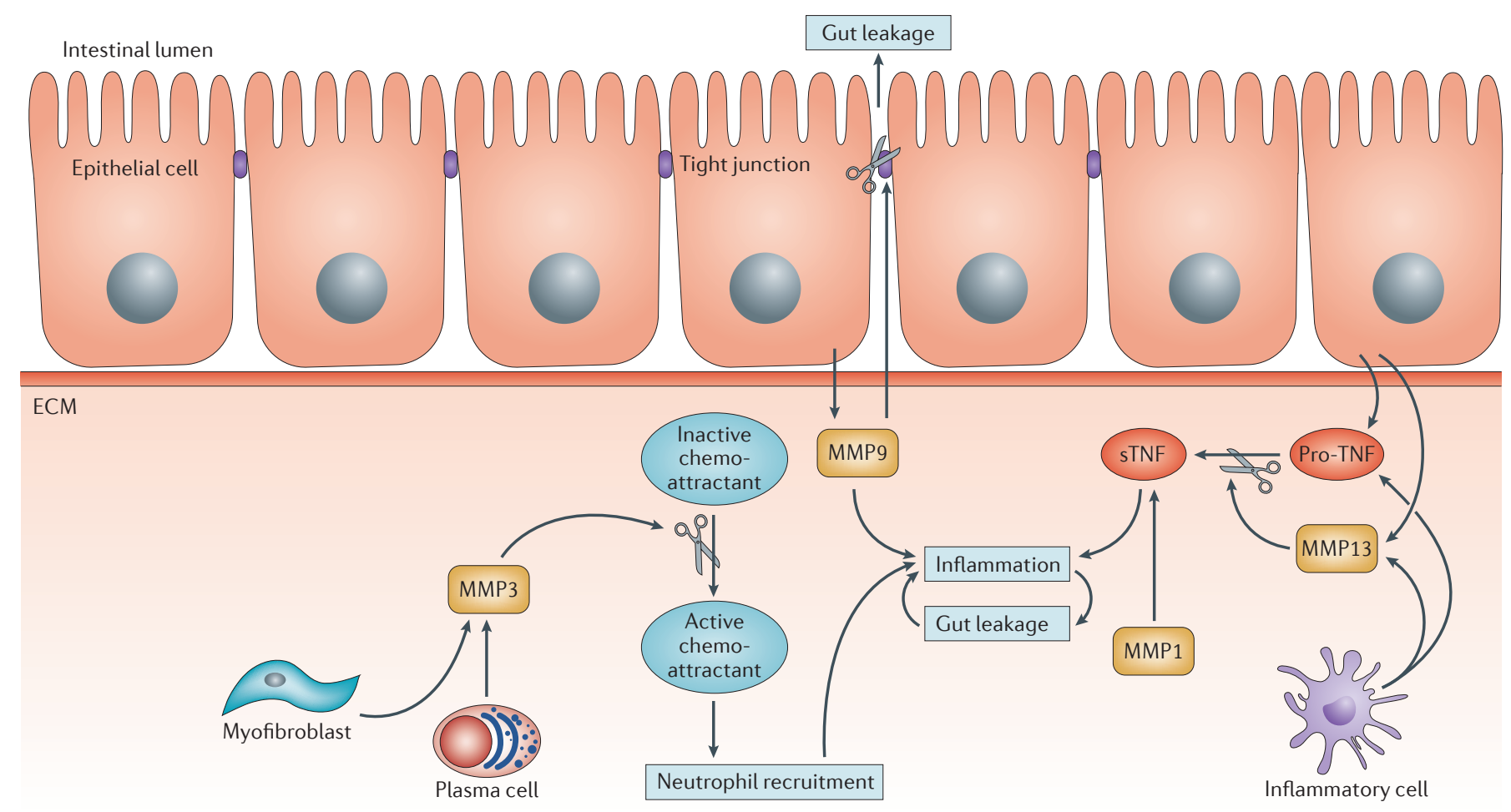

Figure 4 | Schematic overview of the detrimental activities of MMPs in IBD. Several matrix metalloproteinases (MMPs) have a detrimental role in inflammatory bowel disease (IBD). Moreover, based on knockout and inhibitor studies, some MMPs are potential therapeutic targets for IBD treatment. MMP13, which is expressed by epithelial and inflammatory cells, is able to locally activate pro-tumour necrosis factor (pro-TNF) into soluble TNF (sTNF), resulting in increased local inflammation. Epithelial-cell-derived MMP9 was shown to increase mucosal inflammation, whereas blocking MMP9 attenuates the severity of dextran sulphate sodium (DSS)-induced colitis in mice. Plasma cell and myofibroblast-derived MMP3 activates neutrophil chemoattractants from intestinal epithelial cells, which eventually results in increased inflammation. In addition, other MMP activities, such as tight junction or extracellular matrix cleavage, result in increased intestinal permeability and inflammation. ECM, extracellular matrix.

chemoattractant CXC-chemokine ligand 17 (CXCL7) and resulted in increased inflammation in the intestinal epithelium ${ }^{213}$. Interestingly, in vivo administration of MMP3-specific small interfering RNAs (siRNAs) significantly protected mice from DSS-induced colitis ${ }^{214}$.

Another MMP that has been associated with a protective role in IBD is MMP10. Studies in MMP10-deficient mice demonstrated that MMP10 seems to be required for resolution of DSS-induced colonic damage ${ }^{215}$. By contrast, MMP10 downregulation through intraperitoneal injection of MMP10-specific siRNAs did protect against colitis, as evidenced by a smaller reduction in body weight and a reduction in DSS-induced loss of crypts and epithelial layer destruction in treated mice compared with controls ${ }^{214}$. These contradictory results suggest that MMP10 mediates cell-dependent protective and detrimental roles in colitis.

Despite promising results in mouse models of colitis and data from human patients that link some MMPs (for example, MMP9 and MMP3) with disease severity, no clinical trial has studied the use of MMP inhibitors to treat IBD. First, more research is needed to study the therapeutic potential of MMPs in IBD, as not many MMPs have been studied in detail in this context. Moreover, the mouse models that are commonly used to elucidate MMP activity and to evaluate MMP inhibitors are often acute colitis models, whereas fibrosis, which is only present in chronic models, is more likely to be linked with exacerbated MMP activity. It is also important to note that several MMPs have a pivotal role in wound healing, which suggests that therapeutic MMP inhibition could have adverse effects.

NEC is the most common gastrointestinal disease to affect neonates and is associated with destruction of the intestinal barrier ${ }^{216}$. Local TNF concentrations are elevated in NEC and are thought to activate MMPs, which have a role in NEC-associated tissue remodelling and cell migration. MMP3 seemed to be strongly expressed in NEC, which could partly explain the pathophysiological inflammatory response at the onset of $\mathrm{NEC}^{217}$. Other MMPs were also upregulated in NEC samples: MMP7 was upregulated in the epithelium; MMP26 and MMP1 were upregulated in stromal cells; MMP12 was upregulated in both epithelial and stromal cells; and MMP9 was upregulated in inflammatory cells. By contrast, MMP19 was downregulated ${ }^{218}$.

Collagenous colitis is a rare inflammatory disease of the colon associated with chronic and watery diarrhoea. In the inflamed region, lymphocytes are present and the 
subepithelial collagen network is thickened. The excessive diarrhoea is linked to disturbed diffusion and absorption of water owing to thickening of the subepithelial layer. Increased MMP1 expression was observed at specific regions of the inflamed gut ${ }^{219}$.

Diverticulitis is a common digestive disease that involves the formation of pouches or diverticula within the bowel wall. Turnover of ECM plays a pivotal part in this disease. Indeed, mucosal samples from patients with diverticulitis showed increased expression of several MMPs, such as MMP1 and MMP3 (REFS 220,221).

Until now, despite the clear detrimental role of several MMPs in the pathophysiology of NEC, collagenous colitis and diverticulitis, no reports are available on the therapeutic potential of MMP inhibition in these inflammatory diseases. Therefore, further research is needed before therapeutic MMP inhibition can be an option for these gastrointestinal disorders.

MMPs in brain inflammation. The brain has long been thought to be an immunologically privileged organ owing to the BBB, which effectively prevents contact between the peripheral blood and the brain. Impermeability at the $\mathrm{BBB}$ is assured by tight junction protein complexes that closely connect the brain endothelial cells. MMPs have been implicated in a broad range of brain diseases, including stroke, traumatic brain injury, multiple sclerosis, hypoxic ischaemia, Alzheimer's disease, meningitis and spontaneous intracerebral haemorrhage $e^{222-228}$ (TABLE 4). By degrading the neurovascular matrix, MMPs promote injury of the BBB as well as oedema and haemorrhage.

The most extensively studied MMP in brain inflammation is MMP9, and its involvement in ischaemic stroke was recently reviewed ${ }^{229,230}$. Interestingly, MMP9 is increased in both cerebrospinal fluid and plasma of patients with a traumatic brain injury ${ }^{231}$, and peripheral blood MMP9 levels predict lesion volume in acute stroke $^{232}$. Genetic knockout of $M m p 9$ protected the immature brain from BBB rupture and inflammation after hypoxia-ischaemia ${ }^{233}$ and protected from motor deficits in a model of traumatic brain injury ${ }^{234}$. Moreover, MMP9 deficiency diminished BBB leakage, infarct volume and inflammatory cell infiltration after cerebral ischaemia $^{235,236}$. Similarly, MMP9 deficiency attenuated infarct size and behavioural abnormalities, and decreased neural cell adhesion molecule levels after middle cerebral artery occlusion in mice ${ }^{237}$. These observations were confirmed by successful therapeutic targeting of MMP9 via various methods including lentiviral-mediated $M m p 9$ gene silencing $^{238}$, an MMP9-neutralizing monoclonal antibody ${ }^{239}$ and a liposomal formulation containing MMP9-specific siRNA ${ }^{240}$. Similarly, treatment with an MMP9 inhibitor prevented BBB breakdown in Wistar rats subjected to pneumococcal meningitis. Similar results were obtained with an MMP2 and a dual MMP2 and MMP9 inhibitor ${ }^{138}$.

Despite these promising results, it is important to realize that MMP9 and MMP2 are thought to improve repair or regeneration after nervous system injury via several mechanisms, such as cytoskeletal interactions, axonal outgrowth and guidance ${ }^{241}$. These positive effects of MMP9 and MMP2 again highlight the importance of understanding all of the functions of a particular MMP before considering therapeutic inhibition ${ }^{241}$. MMP2 deficiency had no effect on acute brain injury after focal ischaemia ${ }^{242}$. Deficiency of another MMP whose role in brain inflammation has not yet been defined, MMP3, only delayed inflammation and hippocampal neuronal death following global ischaemia ${ }^{243}$.

The potency of several synthetic, often broadspectrum, MMP inhibitors has been studied in mouse and rat models of brain inflammation. SB-3CT, which is a competitive, mechanism-based, dual inhibitor of MMP2 and MMP9, effectively attenuated MMP9 activity, reduced brain lesion volumes and prevented neuronal loss and dendritic degeneration in an experimental mouse model of traumatic brain injury ${ }^{244}$. Similarly, SB-3CT attenuated behavioural impairments and hippocampal loss after traumatic brain injury in rats ${ }^{245}$. It also protected the neurovasculature from embolic focal cerebral ischaemia ${ }^{246}$, but it failed to confer significant neuroprotection after a hypoxic ischaemia insult ${ }^{247}$. Early brain injury following subarachnoid haemorrhage induction, reflected by neuronal cell death, was reduced in the presence of SB-3CT compared with controls ${ }^{248}$.

The broad-spectrum MMP inhibitor doxycycline reduced $\mathrm{BBB}$ permeability owing to reduced loss of collagen type $\mathrm{IV}^{249}$, attenuated recombinant tissue plasminogen activator (tPA)-induced oedema and haemorrhage ${ }^{250}$, and reduced neuronal cell death owing to reduced laminin degradation ${ }^{251}$. Treatment of strokeprone spontaneously hypertensive rats with doxycycline reduced damage after transient cerebral ischaemia ${ }^{252}$. It was recently shown that the protective effects of doxycycline against $\mathrm{BBB}$ damage induced by reperfusion might be related to the upregulation of tight junction proteins and inhibition of MMP2, MMP9 and protein kinase $\mathrm{C}^{253}$. Minocycline treatment reduced brain infarct volume, inflammation and neuronal death in brain ischaemia ${ }^{254,255}$. Minocycline in combination with aspirin protected from the consequences of cerebral ischaemia in animal models of diabetes by inhibiting MMP2 and MMP9 (REF. 256). Doxycycline and minocycline are both broad-spectrum inhibitors of several proteins (including MMPs), and further studies with more specific inhibitors are needed to find which MMPs have therapeutic potential.

Batimastat reduced recombinant tPA-induced haemorrhage and mortality ${ }^{257}$, myelin-binding protein degradation ${ }^{258}$, inflammation and neuronal death ${ }^{243}$, but it impaired recovery from stroke $e^{259}$. Several studies described protection at the level of the $\mathrm{BBB}$ and/or the tight junctions following treatment with BB-1101 - a variant of the broad-spectrum MMP inhibitor batimastat with a smaller allyl $\alpha$-substituent - in brain ischaemia models ${ }^{260-263}$. One study revealed that BB-1101 blocked intranuclear MMP activity, resulting in a positive effect on the oxidation of DNA via reduced poly(ADP-ribose) polymerase 1 (PARP1) and X-ray repair cross complementing group 1 (XRCC1) degradation ${ }^{264}$. However, impaired long-term recovery after stroke was observed in one study ${ }^{263}$. Such a delay was also observed with FN-439, a tetrapeptidyl hydroxamic acid, and was linked to a reduced level of bioavailable vascular endothelial 


\begin{tabular}{|c|c|c|c|}
\hline $\mathrm{Mmp}^{-/-}$or MMP inhibitor & Species & Observations & Refs \\
\hline \multicolumn{4}{|l|}{ TNBS-induced colitis } \\
\hline Batimastat* & Rat & Reduced colonic inflammation & 187 \\
\hline Marimastat* & Rat & Reduced colonic inflammation and MPO activity & 188 \\
\hline AE-941 & Rat & Reduced colonic mucosal damage & 191 \\
\hline Minocycline* & Mouse & $\begin{array}{l}\text { Decreased mortality rate and inhibited pro-inflammatory } \\
\text { cytokine expression in colonic tissues }\end{array}$ & 192 \\
\hline GM6001* & Rat & $\begin{array}{l}\text { Reduced inflammation of colonic mucosa via MMP1 } \\
\text { inhibition }\end{array}$ & 193 \\
\hline $\mathrm{Mmp2}^{-1-} ; \mathrm{Mmp}^{-{ }^{-/-}}$ & Mouse & Resistant to the development of colitis & 206 \\
\hline \multicolumn{4}{|l|}{ DSS-induced colitis } \\
\hline MMP9-specific antibody & Mouse & Attenuated severity of the disease & 105 \\
\hline Mmp13 $13^{-/-}$ & Mouse & Decreased histological score & 169 \\
\hline Minocycline* & Mouse & $\begin{array}{l}\text { Reduced body weight loss, improved colonic histology and } \\
\text { blocked expression of iNOS, pro-inflammatory cytokines } \\
\text { and MMPs from colonic tissues }\end{array}$ & 192 \\
\hline ONO-4817* & Mouse & $\begin{array}{l}\text { Reduced shortening of the colon, infiltration of inflammatory } \\
\text { cells and MPO activity }\end{array}$ & 194 \\
\hline CGS-27023-A* & Rat & $\begin{array}{l}\text { Decreased extent and severity of epithelial injury but no } \\
\text { influence on mucosal repair }\end{array}$ & 195 \\
\hline PGP antagonist & Mouse & Significant reduction in neutrophil infiltration in the intestine & 199 \\
\hline $\mathrm{Mmp}^{-{ }^{-/-}}$ & Mouse & Attenuated intestinal injury & 200 \\
\hline Tg villin-MMPg & Mouse & $\begin{array}{l}\text { Greater weight loss and higher clinical score, histological } \\
\text { score and MPO activity }\end{array}$ & 202 \\
\hline MMP3-specific siRNA & Mouse & Improved clinical score & 214 \\
\hline MMP10-specific siRNA & Mouse & Improved clinical score & 214 \\
\hline Mmp10-1- & Mouse & $\begin{array}{l}\text { Higher propensity for development of dysplastic lesions in } \\
\text { the colon }\end{array}$ & 215 \\
\hline $\mathrm{Mmp2}^{-/-}$ & Mouse & More severe colitis & 201 \\
\hline $\mathrm{Mmp}^{-/-} ; \mathrm{Mmp}^{-/-}$ & Mouse & Resistant to the development of colitis & 206 \\
\hline \multicolumn{4}{|l|}{ Infection-induced colitis } \\
\hline $\mathrm{Mmp2}^{-{ }_{-1}}$ & Mouse & Increased susceptibility to colitis and impaired recovery & 205 \\
\hline $\mathrm{Mmp2}^{-/-} ; \mathrm{Mmp}^{-/-}$ & Mouse & Resistant to the development of colitis & 206 \\
\hline $\mathrm{Mmp}^{-/-}$ & Mouse & $\begin{array}{l}\text { Protected from reductions in foecal microbial diversity in } \\
\text { response to the bacterial enteric infection }\end{array}$ & 204 \\
\hline
\end{tabular}

DSS, dextran sulphate sodium; iNOS, inducible nitric oxide synthetase; MMP, matrix metalloproteinase; MPO, myeloperoxidase; PGP, proline-glycine-proline; siRNA, small interfering RNA; Tg, transgenic; TNBS, 2,4,6-trinitrobenzenesulphonic acid. *These structures are shown in TABLE 1.

growth factor ${ }^{259}$. Another synthetic MMP inhibitor that was evaluated for its ability to treat brain inflammation is GM6001. Similar to the effects observed with other MMP inhibitors, mice treated with GM6001 showed decreased inflammation-induced BBB permeability, neuronal cell death and infarct size, as well as decreased neuroblast migration ${ }^{265-269}$. This inhibitor also prevented the haemorrhagic complications and ameliorated the behavioural abnormalities induced by $\mathrm{PPA}^{270}$. Finally, a novel MMP-inhibitor (Ro 28-2653) that inhibits MT1-MMP (also known as MMP14), MT3-MMP (also known as MMP16), MMP2, MMP8 and MMP9 significantly reduced brain injury when administered in the first 2 days after focal cerebral ischaemia ${ }^{271}$.
Clearly, therapeutic MMP inhibition in acute brain injury and stroke has considerable potential based on available mouse and human data. However, the difficulty will again be to avoid adverse effects of MMP inhibition, especially during stages of recovery. Therefore, detailed analyses of both detrimental and beneficial roles of MMPs must be conducted and inhibition of antitarget MMPs involved in tissue regeneration should be avoided. From the available data, MMP9 inhibition looks to be the most promising; however, it should be noted that several MMPs were, until now, not studied in detail, mainly owing to the lack of suitable detection and inhibitory tools. In addition, it has to be taken into account that the inhibitors will have to reach the central 


\begin{tabular}{|c|c|c|c|}
\hline $\mathrm{MMP}^{-/-}$or MMP inhibitor & Species & Observations & Refs \\
\hline \multicolumn{4}{|l|}{ Pneumococcal meningitis } \\
\hline MMP9 inhibitor & Rat & Reduced BBB dysfunction in the cortex & 138 \\
\hline $\begin{array}{l}\text { Dual MMP2 and MMP9 } \\
\text { inhibitor }\end{array}$ & Rat & Reduced BBB dysfunction in the cortex and hippocampus and enhanced memory & 138 \\
\hline $\mathrm{Mmp}^{-/-}$ & Mouse & Diminished BBB leakage and inflammation owing to reduced white matter degradation & 233 \\
\hline $\mathrm{SB}-3 \mathrm{CT}^{*}$ & Rat & Neuroprotective & 247 \\
\hline GM6001* & Rat & Diminished BBB permeability owing to reduced degradation of ZO1 and occludin & 266 \\
\hline \multicolumn{4}{|l|}{ Traumatic brain injury } \\
\hline \multicolumn{4}{|l|}{ Brain ischaemia } \\
\hline$M m p 9^{-/-}$ & Mouse & $\begin{array}{l}\text { Reduced BBB leakage owing to reduced degradation of white matter components and } \\
\text { occludin }\end{array}$ & 235 \\
\hline$M m p 9^{-/-}$ & Mouse & Reduced BBB leakage, infarct volume and inflammatory cell infiltration & 236 \\
\hline Mmp2 $2^{-/-}$ & Mouse & No difference in acute brain damage & 242 \\
\hline Doxycycline* & Rat & Reduced BBB permeability owing to reduced collagen type IV loss & 249 \\
\hline Doxycycline* & Rat & Reduced BBB permeability and attenuated rtPA-induced oedema and haemorrhage & 250 \\
\hline Doxycycline* & Rat (SP-SHR) & Reduced vascular remodelling and damage & 252 \\
\hline Batimastat* & Rat & Administration 7 days after stroke reduced stroke recovery & 259 \\
\hline BB-1101* & Rat & Attenuated BBB disruption owing to occludin degradation & 260 \\
\hline BB-1101* & Rat & Reduced BBB permeability owing to reduced degradation of claudin 5 and occludin & 262 \\
\hline $\mathrm{FN}-439 *$ & Rat & $\begin{array}{l}\text { Administration } 7 \text { days after stroke reduced stroke recovery owing to a reductuion in } \\
\text { bioavailable VEGF }\end{array}$ & 259 \\
\hline GM6001* & Mouse & Decreased neuroblast migration & 268 \\
\hline Lentiviral MMP9 silencing & Rat & $\begin{array}{l}\text { Reduced BBB disruption, leading to reduced vascular permeability, neuronal cell death } \\
\text { and neurobehavioral deficits }\end{array}$ & 238 \\
\hline Doxycycline* & Mouse & $\begin{array}{l}\text { Reduced BBB permeability and neuronal cell death owing to reduced laminin } \\
\text { degradation }\end{array}$ & 251 \\
\hline Minocycline* & Gerbil & Reduced inflammation and neuronal death & 255 \\
\hline Batimastat* & Mouse & Reduced MBP degradation & 258 \\
\hline \multicolumn{4}{|c|}{ Middle cerebral artery occlusion } \\
\hline$M m p 9^{-/-}$ & Mouse & Attenuated infarction, behavioural abnormalities and decrease of NCAM & 237 \\
\hline MMP9-specific antibody & Rat & Reduced infarct size & 239 \\
\hline MMP9-specific siRNA & Rat & $\begin{array}{l}\text { Reduced BBB dysfunction, cerebral infarction volume, brain water content, mortality rate } \\
\text { and accompanying neurological deficits }\end{array}$ & 240 \\
\hline Batimastat* & Rat & Reduced rtPA-associated haemorrhage and mortality owing to reduced BBB disruption & 257 \\
\hline BB-1101* & Rat & Attenuated initial BBB opening, no effect on delayed BBB opening & 261 \\
\hline
\end{tabular}


Table 4 (cont.) | Effect of MMP inhibitors and MMP deficiency in brain inflammation

\begin{tabular}{|c|c|c|c|}
\hline $\mathrm{MMP}^{-/-}$or MMP inhibitor & Species & Observations & Refs \\
\hline BB-1101* & Rat & Less oxidized DNA owing to reduced PARP1 and XRCC1 degradation & 264 \\
\hline GM6001* & Rat & Reduced brain infarct volume & 265 \\
\hline Ro 28-2653* & Rat & $\begin{array}{l}\text { Reduced infarct oedema volumes and BBB breakdown at day } 3 \text {, but no } \\
\text { differences at day } 6\end{array}$ & 271 \\
\hline Batimastat* & Mouse & Reduced inflammation and neuronal death & 243 \\
\hline \multicolumn{4}{|l|}{ Subarachnoid haemorrhage } \\
\hline MMP9 inhibitor & Rat & Reduced neuronal cell death & 248 \\
\hline
\end{tabular}

nervous system (CNS) to be effective. Delivery of compounds into the CNS can be achieved by intrathecal administration. This enables the bypassing of the BBB and would have the advantage of avoiding systemic side effects of the MMP inhibitors. However, intrathecal drug delivery is an invasive procedure, and thus complications can arise. Several delivery systems have been developed that attempt to bypass the $\mathrm{BBB}^{272,273}$, but this is beyond the scope of this Review.

\section{Future perspectives}

MMP activity is delicately balanced and disturbances can have dramatic effects. Consequently, upregulated MMP activity has an important and often detrimental role in several inflammatory disorders. This makes MMPs attractive therapeutic targets. However, several issues need to be considered before therapeutic MMP inhibitor strategies can be implemented. First, further analyses of the spatiotemporal expression and function of individual MMPs in health and disease must be carried out. Second, specific MMP inhibitors need to be developed to reduce off-target effects.

Despite limitations, such as the possible compensatory increases in other MMPs, the use of knockout mice and other mouse models is often useful to study the role of specific MMPs. Indeed, many single-MMP knockout mice have been generated, yielding a wealth of information on the role of many individual MMPs in particular diseases. Unfortunately, not much has been invested in generating conditional MMP-deficient mice, which might be due to the lack of developmental defects in fullbody knockout mice, with the exception of MT1-MMP. Consequently, MT1-MMP conditional knockout mice were generated ${ }^{274}$. Previous research with conventional MMP knockout mice already enabled researchers to identify MMPs that are possible therapeutic targets and MMPs that are antitargets. Identifying therapeutic targets with minimal adverse effects is unlikely to be easy, as MMPs modify a broad range of signalling pathways and regulate the activity of whole families of cytokines by precise proteolytic processing. Based on the identified substrates, ten of 24 mouse MMPs were suggested to be drug antitargets as their beneficial actions should not be inhibited ${ }^{275}$.

Another important limitation to developing MMP inhibitors is that none of the available animal models reflect the complex human situation. This makes it extremely difficult to extrapolate the outcome of MMP inhibition in animal models to humans. For example, the pathophysiological mechanisms in patients with sepsis are highly individualized. As such, specific tools should be developed in the near future to define these differences and tailor therapeutic strategies accordingly. In addition, not all MMPs have the same expression pattern and substrate repertoire in mice and humans. The most striking example of this is MMP7. Its expression is necessary for intestinal $\alpha$-defensin processing in mice but it is not detected in human Paneth cells ${ }^{178}$. In humans, trypsin was identified as the enzyme responsible for intestinal defensin processing ${ }^{276}$.

To fully understand the role of MMPs in health and disease, it is essential to develop better tools, such as probes for in vivo imaging and more specific antibodies, in order to assess MMP expression and activity during different disease phases ${ }^{12}$. Such tools should preferentially be developed for individual MMPs. Most research has focused on MMP2 and MMP9, not because they are the most important MMPs but owing to the lack of MMP-specific antibodies and the ease of MMP2 and MMP9 zymography ${ }^{277}$.

The currently available imaging probes are based on optical imaging, positron emission tomography, fluorescence resonance energy transfer, single photon emission computed tomography, magnetic resonance imaging ${ }^{278}$ and photoacoustic modalities ${ }^{279}$. Various MMP-activatable optical probes have recently been developed for in vivo MMP imaging, but the use of fluorescent, synthetic, low-molecular-mass MMP inhibitors has also been suggested ${ }^{278,280,281}$. These optical probes are valuable tools to study localization of MMP activity. However, the use of these tools is impeded by the limited availability of probes that are specifically cleaved 
only by clearly defined MMPs and by a paucity of inhibitors that are specific to individual MMPs. In vivo imaging of MMP activity would help to determine the key regulatory points for therapeutic intervention ${ }^{1,282,283}$.

Although the selective inhibition of single targets in early stages of disease might be desirable, more widespread targeting of MMPs might be necessary at intermediate stages, even at the cost of inducing side effects. Moreover, although broad-spectrum inhibition is not desirable owing to possible side effects, an important remaining question is whether single or multiple targets need to be inhibited in certain diseases. Indeed, a better understanding of the overlapping metalloproteinase expression patterns and their effects in health and disease will help to formulate efficacious metalloproteinase inhibitors as therapeutics for immune diseases ${ }^{21}$. To complicate matters, the function of MMPs is often context-dependent. For example, in colitis, MMPs are detrimental during the inflammatory phase of the disease but essential for subsequent wound healing ${ }^{284}$. Consequently, a greater understanding of the involvement of individual MMPs in specific inflammatory disorders is essential to further explore the possibilities of therapeutic MMP inhibition ${ }^{21}$.

Years ago, the MMP research community realized the urgent need for MMP inhibitors of greater specificity. Selectivity is a primary goal of the design of MMP inhibitors in order to improve efficacy and to avoid unwanted side effects. It was originally thought that the musculoskeletal pain observed in clinical trials of anticancer MMP inhibitors was caused by MMP1 inhibition, resulting in the development of MMP1-sparing inhibitors ${ }^{17,18}$. Subsequently, the non-MMP metalloproteinases, such as ADAM and ADAMTS family members, were shown to have a role in the development of musculoskeletal pain $^{52}$ and this was taken into account in ensuing inhibitor development. However, there is still debate about which metalloproteinase is eventually responsible for musculoskeletal pain. AZM551248 treatment of dogs indicated that inhibition of MMP1, MMP2, MMP3 and MMP9 was a key early event in acute fibrosis-type adverse effects that are considered consistent with the clinical findings of musculoskeletal pain in patients ${ }^{285}$. More recently, MMP2, MMP3, MMP7, MMP8, MMP9, MMP11, MMP12, MMP20, MMP26 and MMP28 were recognized as antitargets because inhibition of their activity might result in clinically unwanted side effects and initiation or worsening of disease. Consequently, their essential and beneficial activities should not be inhibited ${ }^{275}$. However, this does not necessarily exclude those MMP as drug targets, but the associated risk/ benefit ratio has to be taken into account, and this can be context-dependent. Also, several ADAM and ADAMTS family members are considered to be antitargets. For example, inhibition of ADAMTS13, which is a metalloproteinase responsible for cleaving large multimers of von Willebrand factor into smaller units, causes thrombotic thrombocytopaenic purpura and genetic dysfunction of ADAMTS13, which results in a rare form of thrombocytopaenic purpura, known as Upshaw-Schülman syndrome ${ }^{286}$.
It is difficult to generate specific MMP inhibitors because of the broad structural similarity of their active sites and the dynamic functional interconnectivity of MMPs with other proteases, their inhibitors and substrates $^{287}$. Although the clinically relevant goal for MMP inhibitor specificity may be to achieve $\sim 1,000$-fold difference in the relative affinity between MMPs, many current inhibitors fall short of this goal ${ }^{60}$.

A third generation of MMP inhibitors is currently being evaluated that are designed to block only the target MMP and to spare the antitargets ${ }^{6,288}$. In addition, offtarget effects can be avoided by attempting to achieve the optimum level of MMP activity for normal physiological processes. This again highlights the need to fully unravel the MMP contribution to tissue homeostasis and their dysregulation in different pathologies, but this requires the development of specific and sensitive quantitative assays to determine MMP activity. Cheminformaticsbased methods (that is, the combination of computational modelling of the drug-protein interactions and methods such as X-ray crystallography) facilitate rational drug design. This approach has already resulted in the identification of different selective inhibitors; for example, MMP13-specific drugs ${ }^{289}$.

Antibody-based MMP inhibitors may offer the selectivity and potency that are required.Interestingly, rational design of antibody-based, function-blocking MMP inhibitors enables targeting of the extracatalytic domains, which are central to proteolytic and non-proteolytic enzyme functions ${ }^{287}$. This may create new therapies that control dysregulated MMP activity without causing severe side effects. Unfortunately, the use of antibodies may be limited by reduced patient convenience as they are administered through the parenteral, rather than oral, administration route. However, the use of these highly specific MMP inhibitors does enable further characterization of the involvement of specific MMPs in pathophysiological processes. Moreover, parenteral administration may not be a barrier for some diseases; for example, patients with septic shock are treated in intensive care units and already have infusion lines for drug delivery ${ }^{290}$.

In addition, to reduce the levels of MMP inhibitors in systemic circulation and the consequent toxicity, it would be interesting to focus on more local administration, which can be achieved by, for example, topical application or targeted delivery. Therefore, it will be essential to determine the exact location of detrimental MMP activity and to develop organ-specific or cell-type-specific delivery systems.

In recent years, MMP signalling cascades have become even more complex as it is increasingly clear that MMPs do not act exclusively outside the cell but can also degrade proteins in the cytoplasm, mitochondria and nucleus ${ }^{12}$. The roles of intracellular MMPs are poorly understood, although recent studies have unravelled some of their functions ${ }^{291}$. Several MMPs ${ }^{292}$, such as MMP2 (REFS 293-295), MMP3 (REF. 296) and MMP12 (REF. 297), have intracellular activity. Although inhibition of intracellular MMP activity is more difficult than inhibition of extracellular MMP activity, this could enable more precise targeting of specific cell types by using cell-type-specific 
markers. Small-domain antibodies, such as nanobodies, may be constructed as bispecific molecules to direct specific MMP-blockers to specific cell types ${ }^{298}$.

In conclusion, we believe that there is still hope for MMP inhibition as a therapeutic approach for the treatment of inflammatory disorders. However, the success of this approach requires a full understanding of the biological processes in each particular disease condition to identify the crucial MMP targets that have to be inhibited. In addition, further research is needed to develop potent and selective agents to avoid the side effects of non-selective MMP inhibitors.
1. Gialeli, C., Theocharis, A. D. \& Karamanos, N. K. Roles of matrix metalloproteinases in cancer progression and their pharmacological targeting. FEBS J. 278, 16-27 (2011).

2. Davies, B., Brown, P. D., East, N., Crimmin, M. J. \& Balkwill, F. R. A synthetic matrix metalloproteinase inhibitor decreases tumor burden and prolongs survival of mice bearing human ovarian carcinoma xenografts. Cancer Res. 53, 2087-2091 (1993).

3. Coussens, L. M., Fingleton, B. \& Matrisian, L. M. Matrix metalloproteinase inhibitors and cancer: trials and tribulations. Science 295, 2387-2392 (2002)

4. Egeblad, M. \& Werb, Z. New functions for the matrix metalloproteinases in cancer progression. Nature Rev. Cancer 2, 161-174 (2002).

5. Fisher, J. F. \& Mobashery, S. Recent advances in MMP inhibitor design. Cancer Metastasis Rev. 25, 115-136 (2006)

6. Overall, C. M. \& Kleifeld, O. Towards third generation matrix metalloproteinase inhibitors for cancer therapy. Br. J. Cancer 94, 941-946 (2006).

7. Overall, C. M. \& Kleifeld, O. Tumour microenvironment - opinion: validating matrix metalloproteinases as drug targets and anti-targets for cancer therapy. Nature Rev. Cancer 6, 227-239 (2006).

8. Pirard, B. Insight into the structural determinants for selective inhibition of matrix metalloproteinases. Drug Discov. Today 12, 640-646 (2007).

9. Rao, B. G. Recent developments in the design of specific matrix metalloproteinase inhibitors aided by structural and computational studies. Curr. Pharm. Design 11, 295-322 (2005).

10. Pavlaki, M. \& Zucker, S. Matrix metalloproteinase inhibitors (MMPIs): the beginning of phase I or the termination of phase III clinical trials. Cancer Metastasis Rev. 22, 177-203 (2003).

11. Overall, C. M. \& Lopez-Otin, C. Strategies for MMP inhibition in cancer: innovations for the post-trial era. Nature Rev. Cancer 2, 657-672 (2002).

12. lyer, R. P., Patterson, N. L., Fields, G. B. ¿ Lindsey, M. L. The history of matrix metalloproteinases: milestones, myths, and misperceptions. Am. J. Physiol. Heart Circ. Physiol. 303, H919-H930 (2012).

13. Hadler-Olsen, E., Winberg, J. O. \& Uhlin-Hansen, L. Matrix metalloproteinases in cancer: their value as diagnostic and prognostic markers and therapeutic targets. Tumour Biol. 34, 2041-2051 (2013).

14. Decock, J., Thirkettle, S., Wagstaff, L. $\delta$ Edwards, D. R. Matrix metalloproteinases: protective roles in cancer. J. Cell. Mol. Med. 15, 1254-1265 (2011).

15. Lopez-Otin, C., Palavalli, L. H. \& Samuels, Y Protective roles of matrix metalloproteinases: from mouse models to human cancer. Cell Cycle $\mathbf{8}$, 3657-3662 (2009).

16. Vanlaere, I. \& Libert, C. Matrix metalloproteinases as drug targets in infections caused by Gram-negative bacteria and in septic shock. Clin. Microbiol. Rev. 22, 224-239 (2009)

17. Drummond, A. H. et al. Preclinical and clinical studies of MMP inhibitors in cancer. Ann. NY Acad. Sci. 878 228-235 (1999)

18. Skiles, J. W., Gonnella, N. C. \& Jeng, A. Y. The design, structure, and clinical update of small molecular weight matrix metalloproteinase inhibitors Curr. Med. Chem. 11, 2911-2977 (2004).

19. Edwards, D. R., Handsley, M. M. \& Pennington, C. J. The ADAM metalloproteinases. Mol. Aspects Med. 29, 258-289 (2008)

20. Tan Ide, A., Ricciardelli, C. \& Russell, D. L. The metalloproteinase ADAMTS1: a comprehensive review of its role in tumorigenic and metastatic pathways. Int. J. Cancer 133, 2263-2276 (2013).

21. Khokha, R., Murthy, A. \& Weiss, A. Metalloproteinases and their natural inhibitors in inflammation and immunity. Nature Rev. Immunol. 13, 649-665 (2013).
22. Gross, J. \& Lapiere, C. M. Collagenolytic activity in amphibian tissues: a tissue culture assay. Proc. Nat Acad Sci. USA 48, 1014-1022 (1962).

23. Sterchi, E. E. Special issue: metzincin metalloproteinases. Mol. Aspects Med. 29, 255-257 (2008)

24. Ra, H. J. \& Parks, W. C. Control of matrix metalloproteinase catalytic activity. Matrix Biol. 26, 587-596 (2007)

25. Fanjul-Fernandez, M., Folgueras, A. R., Cabrera, S. \& Lopez-Otin, C. Matrix metalloproteinases: evolution, gene regulation and functional analysis in mouse models. Biochim. Biophys. Acta 1803, 3-19 (2010).

26. Butler, G. S. \& Overall, C. M. Proteomic identification of multitasking proteins in unexpected locations complicates drug targeting. Nature Rev. Drug Discov. 8, 935-948 (2009)

27. Sorokin, L. The impact of the extracellular matrix on inflammation. Nature Rev. Immunol. 10, 712-723 (2010).

28. Cauwe, B., Van den Steen, P. E. ¿ Opdenakker, G. The biochemical, biological, and pathological kaleidoscope of cell surface substrates processed by matrix metalloproteinases. Crit. Rev. Biochem. Mol. Biol. 42, 113-185 (2007)

29. Page-McCaw, A., Ewald, A. J. \& Werb, Z. Matrix metalloproteinases and the regulation of tissue remodelling. Nature Rev. Mol. Cell Biol. 8, 221-233 (2007)

30. Loffek, S., Schilling, O. \& Franzke, C. W. Series "matrix metalloproteinases in lung health and disease": biological role of matrix metalloproteinases: a critical balance. Eur. Respir. J. 38, 191-208 (2011).

31. Mannello, F. \& Gazzanelli, G. Tissue inhibitors of metalloproteinases and programmed cell death: conundrums, controversies and potential implications. Apoptosis 6, 479-482 (2001).

32. Troeberg, L. \& Nagase, H. Analysis of TIMP expression and activity. Methods Mol. Med. 135, 251-267 (2007).

33. Nagase, H., Visse, R. \& Murphy, G. Structure and function of matrix metalloproteinases and TIMPs. Cardiovascular Res. 69, 562-573 (2006).

34. Murphy, G. Tissue inhibitors of metalloproteinases. Genome Biol. 12, 233 (2011).

35. Leco, K. J. et al. Spontaneous air space enlargement in the lungs of mice lacking tissue inhibitor of metalloproteinases-3 (TIMP-3). J. Clin. Invest. 108, 817-829 (2001)

36. Fata, J. E. et al. Accelerated apoptosis in the Timp-3-deficient mammary gland. J. Clin. Invest 108, 831-841 (2001)

37. Mohammed, F. F. et al. Abnormal TNF activity in Timp $3^{-/-}$mice leads to chronic hepatic inflammation and failure of liver regeneration. Nature Genet. 36 969-977 (2004)

38. Whittaker, M., Floyd, C. D., Brown, P. \& Gearing, A. J. Design and therapeutic application of matrix metalloproteinase inhibitors. Chem. Rev. 99 2735-2776 (1999)

39. Verma, R. P. Hydroxamic acids as matrix metalloproteinase inhibitors. EXS 103, 137-176 (2012).

40. Macaulay, V. M. et al. Phase I study of intrapleural batimastat (BB-94), a matrix metalloproteinase inhibitor, in the treatment of malignant pleural effusions. Clin. Cancer Res. 5, 513-520 (1999).

41. Acharya, M. R., Venitz, J., Figg, W. D. \& Sparreboom, A. Chemically modified tetracyclines as inhibitors of matrix metalloproteinases. Drug Resist. Updat. 7, 195-208 (2004).

42. Eccles, S. A. et al. Control of lymphatic and hematogenous metastasis of a rat mammary carcinoma by the matrix metalloproteinase inhibitor batimastat (BB-94). Cancer Res. 56, 2815-2822 (1996).

43. Sledge, G. W. et al. Effect of matrix metalloproteinase inhibitor batimastat on breast cancer regrowth and metastasis in athymic mice. J. Natl Cancer Inst. 87, 1546-1550 (1995).
44. Low, J. A., Johnson, M. D., Bone, E. A. ¿ Dickson, R. B. The matrix metalloproteinase inhibitor batimastat (BB-94) retards human breast cancer solid tumor growth but not ascites formation in nude mice. Clin. Cancer Res. 2, 1207-1214 (1996).

45. Watson, S. A. et al. Inhibition of organ invasion by the matrix metalloproteinase inhibitor batimastat (BB-94) in two human colon carcinoma metastasis models. Cancer Res. 55, 3629-3633 (1995).

46. Chirivi, R. G. et al. Inhibition of the metastatic spread and growth of B16-BL6 murine melanoma by a synthetic matrix metalloproteinase inhibitor. Int. J. Cancer 58, 460-464 (1994).

47. Taraboletti, G. et al. Inhibition of angiogenesis and murine hemangioma growth by batimastat, a synthetic inhibitor of matrix metalloproteinases. J. Natl Cancer Inst. 87, 293-298 (1995).

48. Mannello, F, Tonti, G \& Papa, S. Matrix metalloproteinase inhibitors as anticancer therapeutics. Curr. Cancer Drug Targets 5 , 285-298 (2005).

49. Vihinen, P., Ala-aho, R. \& Kahari, V. M. Matrix metalloproteinases as therapeutic targets in cancer. Curr. Cancer Drug Targets 5, 203-220 (2005).

50. Sparano, J. A. et al. Randomized phase III trial of marimastat versus placebo in patients with metastatic breast cancer who have responding or stable disease after first-line chemotherapy: Eastern Cooperative Oncology Group trial E2196. J. Clin. Oncol. 22, 4683-4690 (2004).

51. Goffin, J. R. et al. Phase I trial of the matrix metalloproteinase inhibitor marimastat combined with carboplatin and paclitaxel in patients with advanced non-small cell lung cancer. Clin. Cancer Res. 11, 3417-3424 (2005)

52. Fingleton, B. MMPs as therapeutic targets - still a viable option? Semin. Cell Dev. Biol. 19, 61-68 (2008).

53. Fingleton, B. Matrix metalloproteinases: roles in cancer and metastasis. Front. Biosci. 11, 479-491 (2006).

54. Kruger, A., Kates, R. E. \& Edwards, D. R. Avoiding spam in the proteolytic internet: future strategies for anti-metastatic MMP inhibition. Biochim. Biophys. Acta 1803, 95-102 (2010).

55. Eatock, M. et al. A dose-finding and pharmacokinetic study of the matrix metalloproteinase inhibitor MMI270 (previously termed CGS27023A) with 5-FU and folinic acid. Cancer Chemother. Pharmacol. 55, 39-46 (2005)

56. Hoekstra, R., Eskens, F. A. \& Verweij, J. Matrix metalloproteinase inhibitors: current developments and future perspectives. Oncol. 6, 415-427 (2001).

57. Close, D. R. Matrix metalloproteinase inhibitors in rheumatic diseases. Ann. Rheum. Dis. 60, iii62-iii67 (2001).

58. Li, J., et al. Synthesis and SAR of highly selective MMP-13 inhibitors. Bioorg. Med. Chem. Lett. 15 4961-4966 (2005).

59. de Melo, E. B. A OSAR study of matrix metalloproteinases type 2 (MMP-2) inhibitors with cinnamoyl pyrrolidine derivatives. Scientia pharmaceutica 80, 265-281 (2012).

60. Jacobsen, J. A., Major Jourden, J. L., Miller, M. T. $\&$ Cohen, S. M. To bind zinc or not to bind zinc: an examination of innovative approaches to improved metalloproteinase inhibition. Biochim. Biophys. Acta 1803, 72-94 (2010)

61. Naglich, J. G. et al. Inhibition of angiogenesis and metastasis in two murine models by the matrix metalloproteinase inhibitor, BMS-275291. Cancer Res. 61, 8480-8485 (2001)

62. Miller, K. D. et al. A randomized phase II feasibility trial of BMS-275291 in patients with early stage breast cancer. Clin. Cancer Res. 10, 1971-1975 (2004). 
63. Leighl, N. B. et al. Randomized phase III study of matrix metalloproteinase inhibitor BMS-275291 in combination with paclitaxel and carboplatin in advanced non-small-cell lung cancer: National Cancer Institute of Canada-Clinical Trials Group Study BR. 18 J. Clin. Oncol. 23, 2831-2839 (2005).

64. Lutz, J. et al. Inhibition of matrix metalloproteinases during chronic allograft nephropathy in rats. Transplantation 79, 655-661 (2005).

65. Lee, M. et al. Synthesis of chiral 2-(4-phenoxyphenylsulfonylmethyl)thiiranes as selective gelatinase inhibitors. Org. Lett. 7, 4463-4465 (2005)

66. Ikejiri, M. et al. Potent mechanism-based inhibitors for matrix metalloproteinases. J. Biol. Chem. $\mathbf{2 8 0}$, 33992-34002 (2005)

67. Ikejiri, M. et al. Design, synthesis, and evaluation of a mechanism-based inhibitor for gelatinase $A$. J. Org. Chem. 70, 5709-5712 (2005).

68. Grams, F. et al. Pyrimidine-2,4,6-triones: a new effective and selective class of matrix metalloproteinase inhibitors. Biol. Chem. 382, 1277-1285 (2001).

69. Lein, M. et al. The new synthetic matrix metalloproteinase inhibitor (Roche 28-2653) reduces tumor growth and prolongs survival in a prostate cancer standard rat model. Oncogene 21, 2089-2096 (2002)

70. Abramjuk, C. et al. Matrix metalloproteinase inhibitor Ro 28-2653 in combination with estramustine: tumor-reducing effects on hormone-sensitive prostate cancer in rats. Anticancer Drugs 16, 855-861 (2005).

71. Kilian, M. et al. Matrix metalloproteinase inhibitor RO 28-2653 decreases liver metastasis by reduction of MMP-2 and MMP-9 concentration in BOP-induced ductal pancreatic cancer in Syrian Hamsters: inhibition of matrix metalloproteinases in pancreatic cancer. Prostaglandins Leukot. Essent. Fatty Acids 75, 429-434 (2006)

72. Maquoi, E. et al. Anti-invasive, antitumoral, and antiangiogenic efficacy of a pyrimidine-2,4,6-trione derivative, an orally active and selective matrix metalloproteinases inhibitor. Clin. Cancer Res. 10, 4038-4047 (2004).

73. De Savi, C. et al. Hydantoin based inhibitors of MMP13 - discovery of AZD6605. Bioorg. Med. Chem. Lett. 23, 4705-4712 (2013).

74. Hu, Y. et al. Potent, selective, and orally bioavailable matrix metalloproteinase-13 inhibitors for the treatment of osteoarthritis. Bioorg. Med. Chem. 13, 6629-6644 (2005)

75. Li, J. et al. Synthesis and SAR of highly selective MMP-13 inhibitors. Bioorg. Med. Chem. Lett. 15, 4961-4966 (2005)

76. Wu, J. et al. Identification of potent and selective MMP-13 inhibitors. Bioorg. Med. Chem. Lett. 15, 4105-4109 (2005)

77. Dive, V. et al. Phosphinic peptides as zinc metalloproteinase inhibitors. Cell. Mol. Life SCi. 61, 2010-2019 (2004)

78. Reiter, L. A. et al. Phosphinic acid-based MMP-13 inhibitors that spare MMP-1 and MMP-3. Bioorg. Med. Chem. Lett. 13, 2331-2336 (2003).

79. Dive, V. et al. Dosing and scheduling influence the antitumor efficacy of a phosphinic peptide inhibitor of matrix metalloproteinases. Int J. Cancer 113 , 775-781 (2005)

80. Sorsa, T. et al. Matrix metalloproteinases: contribution to pathogenesis, diagnosis and treatment of periodontal inflammation. Ann. Med. 38, 306-321 (2006).

81. Rudek, M. A. et al. Phase I clinical trial of oral COL-3, a matrix metalloproteinase inhibitor, in patients with refractory metastatic cancer. J. Clin. Oncol. 19, 584-592 (2001)

82. Schechter, I. \& Berger, A. On the active site of proteases. 3. Mapping the active site of papain; specific peptide inhibitors of papain. Biochem. Biophys. Res. Commun. 32, 898-902 (1968).

83. Aureli, L. et al. Structural bases for substrate and inhibitor recognition by matrix metalloproteinases. Curr. Med. Chem. 15, 2192-2222 (2008).

84. Park, H. I. et al. The intermediate S1' pocket of the endometase/matrilysin-2 active site revealed by enzyme inhibition kinetic studies, protein sequence analyses, and homology modeling. J. Biol. Chem. 278, 51646-51653 (2003)

85. Gupta, S. P. \& Patil, V. M. Specificity of binding with matrix metalloproteinases. EXS 103, 35-56 (2012).

86. Gupta, S. P. Matrix metalloproteinase inhibitors: specificity of binding and structure-activity relationships. EXS 103, v-vi (2012).
87. Gege, C. et al. Discovery and evaluation of a non-Zn chelating, selective matrix metalloproteinase 13 (MMP-13) inhibitor for potential intra-articular treatment of osteoarthritis. J. Med. Chem. 55, 709-716 (2012).

88. Jungel, A. et al. Effect of the oral application of a highly selective MMP-13 inhibitor in three different animal models of rheumatoid arthritis. Ann. Rheum. Dis. 69, 898-902 (2010)

89. Schnute, M. E. et al. Discovery of (pyridin-4-yl)$2 \mathrm{H}$-tetrazole as a novel scaffold to identify highly selective matrix metalloproteinase- 13 inhibitors for the treatment of osteoarthritis. Bioorg. Med. Chem. Lett. 20, 576-580 (2010).

90. Fabre, B. et al. An integrated computational and experimental approach to gaining selectivity for MMP-2 within the gelatinase subfamily. Chembiochem. 15, 399-412 (2014).

91. Roth, J. et al. Identification of novel, exosite-binding matrix metalloproteinase-13 inhibitor scaffolds. Bioorg. Med Chem Lett 21, 7180-7184 (2011).

92. Udi, Y. et al. Unraveling hidden regulatory sites in structurally homologous metalloproteases. J. Mol. Biol. 425, 2330-2346 (2013)

93. Ndinguri, M. W., Bhowmick, M., Tokmina-Roszyk, D. Robichaud, T. K. \& Fields, G. B. Peptide-based selective inhibitors of matrix metalloproteinasemediated activities. Molecules 17, 14230-14248 (2012)

94. Koivunen, E. et al. Tumor targeting with a selective gelatinase inhibitor. Nature Biotech. 17, 768-774 (1999)

95. Suojanen, J., Salo, T., Koivunen, E., Sorsa, T. \& Pirila, E. A novel and selective membrane typematrix metalloproteinase (MT1-MMP) inhibitor reduces cancer cell motility and tumor growth. Cancer Biol. Ther. 8, 2362-2370 (2009).

96. Devy, L. \& Dransfield, D. T. New strategies for the next generation of matrix-metalloproteinase inhibitors: selectively targeting membrane-anchored MMPs with therapeutic antibodies. Biochem. Res. Int. 2011 191670 (2011)

97. Hoet, R. M. et al. Generation of high-affinity human antibodies by combining donor-derived and synthetic complementarity-determining-region diversity. Nature Biotech. 23, 344-348 (2005)

98. Devy, L. et al. Selective inhibition of matrix metalloproteinase-14 blocks tumor growth, invasion, and angiogenesis. Cancer Res. 69, 1517-1526 (2009)

99. Ingvarsen, S. et al. Targeting a single function of the multifunctional matrix metalloprotease MT1-MMP: impact on lymphangiogenesis. J. Biol. Chem. 288 10195-10204 (2013)

100. Kaimal, R. et al. Selective blockade of matrix metalloprotease- 14 with a monoclonal antibody abrogates invasion, angiogenesis, and tumor growth in ovarian cancer. Cancer Res. 73, 2457-2467 (2013)

101. Basu, B. et al. Inhibition of MT1-MMP activity using functional antibody fragments selected against its hemopexin domain. Int. J. Biochem. Cell Biol. 44, 393-403 (2012)

102. Hu, J., Van den Steen, P. E., Houde, M., Ilenchuk, T. T. ¿ Opdenakker $\mathrm{G}$. Inhibitors of gelatinase B/matrix metalloproteinase-9 activity comparison of a peptidomimetic and polyhistidine with single-chain derivatives of a neutralizing monoclonal antibody. Biochem. Pharmacol. 67, 1001-1009 (2004).

103. Martens, E. et al. A monoclonal antibody inhibits gelatinase B/MMP-9 by selective binding to part of the catalytic domain and not to the fibronectin or zinc binding domains. Biochim. Biophys. Acta 1770 178-186 (2007).

104. Shiryaev, S. A. et al. A monoclonal antibody interferes with TIMP-2 binding and incapacitates the MMP-2-activating function of multifunctional, pro-tumorigenic MMP-14/MT1-MMP. Oncogenesis 2, e80 (2013)

105. Sela-Passwell, N. et al. Antibodies targeting the catalytic zinc complex of activated matrix metalloproteinases show therapeutic potential. Nature Med. 18, 143-147 (2012).

106. Naito, S. et al. Development of a neutralizing antibody specific for the active form of matrix metalloproteinase-13. Biochemistry $51,8877-8884$ (2012)

107. Bu, Z. et al. SZ-117, a monoclonal antibody against matrix metalloproteinase- 2 inhibits tumor cellmediated angiogenesis. Hybridoma 31, 63-67 (2012)
108. Tchetverikov, I. et al. Active MMPs captured by alpha 2 macroglobulin as a marker of disease activity in rheumatoid arthritis. Clin. Exp. Rheumatol 21, 711-718 (2003)

109. Etique, N., Verzeaux, L., Dedieu, S. \& Emonard, H. LRP-1: a checkpoint for the extracellular matrix proteolysis. BioMed Res. Int. 2013, 152163 (2013).

110. Birkenmeier, G. et al. Polymyxin B-conjugated $\alpha 2$-macroglobulin as an adjunctive therapy to sepsis: modes of action and impact on lethality. J. Pharmacol. Exp. Ther. 318, 762-771 (2006).

111. Webb, D. J. \& Gonias, S. L. A modified human alpha 2-macroglobulin derivative that binds tumor necrosis factor-alpha and interleukin-1 beta with high affinity in vitro and reverses lipopolysaccharide toxicity in vivo in mice. Lab. Invest. 78, 939-948 (1998).

112. Amour, A. et al. The in vitro activity of ADAM-10 is inhibited by TIMP-1 and TIMP-3. FEBS Lett. 473, 275-279 (2000)

113. Smookler, D. S. et al. Tissue inhibitor of metalloproteinase 3 regulates TNF-dependent systemic inflammation. J. Immunol. 176, 721-725 (2006).

114. Vanhoutte, D. \& Heymans, S. TIMPs and cardiac remodeling: 'Embracing the MMP-independent-side of the family'. J. Mol. Cell Cardiol. 48, 445-453 (2010).

115. Moore, C. S. \& Crocker, S. J. An alternate perspective on the roles of TIMPs and MMPs in pathology. Am. J. Pathol. 180, 12-16 (2012).

116. Stetler-Stevenson, W. G. Tissue inhibitors of metalloproteinases in cell signaling: metalloproteinaseindependent biological activities. Sci. Signal. 1, re6 (2008).

117. Seo, D. W. et al. TIMP-2 mediated inhibition of angiogenesis: an MMP-independent mechanism. Cell 114, 171-180 (2003).

118. Stetler-Stevenson, W. G. \& Seo, D. W. TIMP-2: an endogenous inhibitor of angiogenesis. Trends Mol. Med. 11, 97-103 (2005).

119. Nieuwesteeg, M. A., Walsh, L. A., Fox, M. A. \& Damjanovski, S. Domain specific overexpression of TIMP-2 and TIMP-3 reveals MMP-independent functions of TIMPs during Xenopus laevis development. Biochem. Cell Biol. 90, 585-595 (2012).

120. Butler, G. S. et al. The TIMP2 membrane type metalloproteinase "receptor" regulates the concentration and efficient activation of progelatinase A. A kinetic study. J. Biol. Chem. 273, 871-880 (1998).

121. Hu, J., Van den Steen, P. E., Sang, Q. X. \& Opdenakker, G. Matrix metalloproteinase inhibitor as therapy for inflammatory and vascular diseases. Nature Rev. Drug Discov. 6, 480-498 (2007).

122. Qiu, Z., Hu, J., Van den Steen, P. E. \& Opdenakker, G. Targeting matrix metalloproteinases in acute inflammatory shock syndromes. Comb. Chem. High Throughput Screen. 15, 555-570 (2012).

123. Vandenbroucke, R. E., Dejonckheere, E. \& Libert, C. A therapeutic role for matrix metalloproteinase inhibitors in lung diseases? Eur. Respir. J. 38 1200-1214 (2011)

124. Dejonckheere, E., Vandenbroucke, R. E. \& Libert, C. Matrix metalloproteinases as drug targets in ischemia/reperfusion injury. Drug Discov. Today 16 762-778 (2011)

125. Newby, A. C. Matrix metalloproteinase inhibition therapy for vascular diseases. Vascul. Pharmacol. 56, 232-244 (2012)

126. Yabluchanskiy, A., Ma, Y., lyer, R. P., Hall, M. E. \& Lindsey, M. L. Matrix metalloproteinase-9. many shades of function in cardiovascular disease. Physiology 28, 391-403 (2013).

127. Halade, G. V., Jin, Y. F. \& Lindsey, M. L. Matrix metalloproteinase (MMP)-9: a proximal biomarker for cardiac remodeling and a distal biomarker for inflammation. Pharmacol. Ther 139, 32-40 (2013).

128. Nissinen, L. \& Kahari, V. M. Matrix metalloproteinases in inflammation. Biochim. Biophys. Acta 1840 , 2571-2580 (2014).

129. Angus, D. C. \& van der Poll, T. Severe sepsis and septic shock. N. Engl. J. Med. 369, 2063 (2013).

130. Marti-Carvajal, A. J., Sola, I., Gluud, C., Lathyris, D. \& Cardona, A. F. Human recombinant protein C for severe sepsis and septic shock in adult and paediatric patients. Cochrane Database Syst. Rev. 12 , CD004388 (2012)

131. Deutschman, C. S. Steroid responses in sepsis: some novel thinking that may provide new insight. Crit. Care 17, 147 (2013) 
132. Seok, J. et al. Genomic responses in mouse models poorly mimic human inflammatory diseases. Proc. Natl Acad. Sci. USA 110, 3507-3512 (2013)

133. Dejager, L., Pinheiro, I., Dejonckheere, E. \& Libert, C. Cecal ligation and puncture: the gold standard model for polymicrobial sepsis? Trends Microbiol. 19, 198-208 (2011)

134. Okamoto, T. et al. Activation of human matrix metalloproteinases by various bacterial proteinases. J. Biol. Chem. 272, 6059-6066 (1997).

135. Elkington, P. T., Green, J. A. \& Friedland, J. S Analysis of matrix metalloproteinase secretion by macrophages. Methods Mol. Biol. 531, 253-265 (2009).

136. Lalu, M. M., Cena, J., Chowdhury, R., Lam, A. \& Schulz, R. Matrix metalloproteinases contribute to endotoxin and interleukin-1 $\beta$ induced vascular dysfunction. Br. J. Pharmacol. 149, 31-42 (2006).

137. Dubois, B. et al. Gelatinase B deficiency protects against endotoxin shock. Eur. J. Immunol. 32, 2163-2171 (2002).

138. Barichello, T. et al. Inhibition of matrix metalloproteinases- 2 and -9 prevents cognitive impairment induced by pneumococcal meningitis in Wistar rats. Exp. Biol. Med. 239, 225-231 (2014).

139. Pagenstecher, A., Stalder, A. K., Kincaid, C. L., Volk, B. \& Campbell, I. L. Regulation of matrix metalloproteinases and their inhibitor genes in lipopolysaccharide-induced endotoxemia in mice. Am. J. Pathol. 157, 197-210 (2000)

140. Rahman, M. et al. Metalloproteinases regulate CD40L shedding from platelets and pulmonary recruitment of neutrophils in abdominal sepsis. Inflamm. Res. $\mathbf{6 1}$, 571-579 (2012)

141. Chen, J. et al. Biodistribution of radiolabeled [(3)H] CMT-3 in rats. Curr. Med. Chem. 8, 253-256 (2001).

142. Liu, Y. et al. The lipophilicity, pharmacokinetics, and cellular uptake of different chemically-modified tetracyclines (CMTs). Curr. Med. Chem. 8, 243-252 (2001).

143. Steinberg, J. et al. Metalloproteinase inhibition reduces lung injury and improves survival after cecal ligation and puncture in rats. J. Surg. Res. 111 , 185-195 (2003)

144. Vandooren, J., Van den Steen, P. E. \& Opdenakker, C. Biochemistry and molecular biology of gelatinase $B$ or matrix metalloproteinase-9 (MMP-9): the next decade. Crit. Rev. Biochem. Mol. Biol. 48, 222-272 (2013).

145. Muhl, D. et al. Dynamic changes of matrix metalloproteinases and their tissue inhibitors in severe sepsis. J. Crit. Care 26, 550-555 (2011).

146. Maitra, S. R., Jacob, A., Zhou, M. \& Wang, P. Modulation of matrix metalloproteinase- 9 and tissue inhibitor of matrix metalloproteinase-1 in sepsis. Int. J. Clin. Exp. Med. 3, 180-185 (2010).

47. Hu, J., Van den Steen, P. E., Dillen, C. \& Opdenakker, G. Targeting neutrophil collagenase matrix metalloproteinase- 8 and gelatinase $\mathrm{B} /$ matrix metalloproteinase-9 with a peptidomimetic inhibitor protects against endotoxin shock. Biochem. Pharmacol. 70, 535-544 (2005).

148. Renckens, R. et al. Matrix metalloproteinase-9 deficiency impairs host defense against abdominal sepsis. J. Immunol. 176, 3735-3741 (2006).

149. Dal-Pizzol, F. et al. Matrix metalloproteinase-2 and metalloproteinase-9 activities are associated with blood-brain barrier dysfunction in an animal model of severe sepsis. Mol. Neurobiol. 48, 62-70 (2013).

150. Tressel, S. L. et al. A matrix metalloprotease-PAR1 system regulates vascular integrity, systemic inflammation and death in sepsis. EMBO Mol. Med. 3, 370-384 (2011)

151. Schouten, M., Wiersinga, W. J., Levi, M. \& van der Poll, T Inflammation, endothelium, and coagulation in sepsis. J. Leukoc. Biol. 83, 536-545 (2008)

152. Vandenbroucke, R. E., Dejager, L. \& Libert, C. The first MMP in sepsis. EMBO Mol. Med. 3 367-369 (2011)

153. Fanjul-Fernandez, M. et al. Matrix metalloproteinase $\mathrm{Mmp}-1 \mathrm{a}$ is dispensable for normal growth and fertility in mice and promotes lung cancer progression by modulating inflammatory responses. J. Biol. Chem. 288, 14647-14656 (2013).

154. Van Lint, P. \& Libert, C. Matrix metalloproteinase-8: cleavage can be decisive. Cytokine Growth Factor Rev. 17, 217-223 (2006)

155. Dejonckheere, E., Vandenbroucke, R. E. \& Libert, C. Matrix metalloproteinase 8 has a central role in inflammatory disorders and cancer progression. Cytokine Growth Factor Rev. 22, 73-81 (2011).
156. Tester, A. M. et al. LPS responsiveness and neutrophil chemotaxis in vivo require PMN MMP-8 activity. PLOS ONE 2, e312 (2007)

157. Lauhio, A. et al. Serum MMP-8, -9 and TIMP-1 in sepsis: high serum levels of MMP-8 and TIMP-1 are associated with fatal outcome in a multicentre, prospective cohort study. Hypothetical impact of tetracyclines. Pharmacol. Res. 64, 590-594 (2011).

158. Solan, P. D. et al. A novel role for matrix metalloproteinase-8 in sepsis. Crit. Care Med. 40, 379-387 (2012).

159. Punyadeera, C. et al. A biomarker panel to discriminate between systemic inflammatory response syndrome and sepsis and sepsis severity. J. Emerg. Trauma Shock 3, 26-35 (2010).

160. Hoffmann, U., Brueckmann, M. \& Borggrefe, M Matrix metalloproteinases and their inhibitors: promising novel biomarkers in severe sepsis? Crit. Care 13, 1006 (2009)

161. Vandenbroucke, R. E et al. Matrix metalloprotease 8-dependent extracellular matrix cleavage at the blood-CSF barrier contributes to lethality during systemic inflammatory diseases. J. Neurosci. 32, 9805-9816 (2012)

162. Gonzalez-Lopez, A. et al. MMP-8 deficiency increases TLR/RAGE ligands S100A8 and S100A9 and exacerbates lung inflammation during endotoxemia. PLOS ONE 7, e39940 (2012)

163. Singh, A. et al. Collagenase-3 (MMP-13) deficiency protects $\mathrm{C} 57 \mathrm{BL} / 6$ mice from antibody-induced arthritis. Arthritis Res. Ther 15, R222 (2013).

164. Toriseva, M. et al. MMP-13 regulates growth of wound granulation tissue and modulates gene expression signatures involved in inflammation, proteolysis, and cell viability. PLoS ONE 7, e42596 (2012).

165. Li, N. G., Tang, Y. P. \& Duan, J. A. New selective inhibitors of MMP-13 for inflammatory diseases: a patent evaluation (W02012151158). Expert Opin. Ther. Pat. 23, 669-675 (2013)

166. Muddasani, P., Norman, J. C., Ellman, M., van Wijnen, A. J. \& Im, H. J. Basic fibroblast growth factor activates the MAPK and NFKB pathways that converge on Elk-1 to control production of matrix metalloproteinase- 13 by human adult articular chondrocytes. J. Biol. Chem. 282, 31409-31421 (2007).

167. Ahmad, R., Sylvester, J. \& Zafarullah, M. MyD88, IRAK1 and TRAF6 knockdown in human chondrocytes inhibits interleukin-1-induced matrix metalloproteinase-13 gene expression and promoter activity by impairing MAP kinase activation. Cell Signal. 19, 2549-2557 (2007).

168. Uhlenhaut, N. H. et al. Insights into negative regulation by the glucocorticoid receptor from genome-wide profiling of inflammatory cistromes. $\mathrm{Mol}$. Cell 49, 158-171 (2013)

169. Vandenbroucke, R. E. et al. Matrix metalloproteinase 13 modulates intestinal epithelial barrier integrity in inflammatory diseases by activating TNF. EMBO Mol. Med. 5, 932-948 (2013).

170. Carrico, C. J., Meakins, J. L., Marshall, J. C., Fry, D $\&$ Maier, R. V. Multiple-organ-failure syndrome. Arch. Surg. 121, 196-208 (1986).

171. Deitch, E. A. \& Berg, R. Bacterial translocation from the gut: a mechanism of infection. J. Burn Care Rehabil. $\mathbf{8}$, 475-482 (1987).

172. Gearing, A. J. et al. Matrix metalloproteinases and processing of pro-TNF- $\alpha$. J. Leukoc. Biol. 57. 774-777 (1995)

173. Chandler, S Cossins, J. Lury, J. \& Wells, C Macrophage metalloelastase degrades matrix and myelin proteins and processes a tumour necrosis factor- $\alpha$ fusion protein. Biochem. Biophys. Res. Commun. 228, 421-429 (1996).

174. d'Ortho, M. P. et al. Membrane-type matrix metalloproteinases 1 and 2 exhibit broad-spectrum proteolytic capacities comparable to many matrix metalloproteinases. Eur. J. Biochem. 250, 751-757 (1997).

175. Tam, E. M., Morrison, C. J., Wu, Y. I., Stack, M. S. \& Overall, C. M. Membrane protease proteomics: isotope-coded affinity tag MS identification of undescribed MT1-matrix metalloproteinase substrates. Proc. Natl Acad. Sci. USA 101, 6917-6922 (2004).

176. Becker-Pauly, C. \& Rose-John, S. TNF $\alpha$ cleavage beyond TACE/ADAM 17: matrix metalloproteinase 13 is a potential therapeutic target in sepsis and colitis. EMBO Mol. Med. 5, 902-904 (2013)

177. Marchenko, G. N. \& Strongin, A. Y. MMP-28, a new human matrix metalloproteinase with an unusual cysteine-switch sequence is widely expressed in tumors. Gene 265, 87-93 (2001)
178. Vandenbroucke, R. E. et al. Pro-inflammatory effects of matrix metalloproteinase 7 in acute inflammation. Mucosal Immunol. 7, 579-588 (2014).

179. Gaddnas, F. P. et al. Matrix-metalloproteinase-2, -8 and -9 in serum and skin blister fluid in patients with severe sepsis. Crit. Care 14, R49 (2010)

180. MacDonald, T. T., Monteleone, I., Fantini, M. C. $\&$ Monteleone, G. Regulation of homeostasis and inflammation in the intestine. Gastroenterology 140, 1768-1775 (2011)

181. Giuffrida, P., Biancheri, P. \& Macdonald, T. T. Proteases and small intestinal barrier function in health and disease. Curr. Opin. Gastroenterol. 30, 147-153 (2014)

182. Medina, C. \& Radomski, M. W. Role of matrix metalloproteinases in intestinal inflammation. J. Pharmacol. Exp. Ther. 318, 933-938 (2006).

183. Pedersen, J., Coskun, M., Soendergaard, C., Salem, M. \& Nielsen, O. H. Inflammatory pathways of importance for management of inflammatory bowel disease. World J Gastroenterol. 20,64-77 (2014).

184. Billiet, T., Rutgeerts, P., Ferrante, M., Van Assche, G $\&$ Vermeire, S. Targeting TNF- $\alpha$ for the treatment of inflammatory bowel disease. Expert Opin. Biol. Ther. 14, 75-101 (2014).

185. Podolsky, D. K. Beyond tumor necrosis factor: next-generation biologic therapy for inflammatory bowel disease. Dig. Dis. 27, 366-369 (2009).

186. Morgan, A. R. et al. Genetic variations in matrix metalloproteinases may be associated with increased risk of ulcerative colitis. Hum. Immunol. 72 , 1117-1127 (2011)

187. Sykes, A. P. et al. The effect of an inhibitor of matrix metalloproteinases on colonic inflammation in a trinitrobenzenesulphonic acid rat model of inflammatory bowel disease. Aliment. Pharmacol. Ther. 13, 1535-1542 (1999).

188. Di Sebastiano, P. et al. Beneficial effects of batimasta (BB-94), a matrix metalloproteinase inhibitor, in rat experimental colitis. Digestion 63, 234-239 (2001).

189. Gingras, D. et al. Neovastat - a novel antiangiogenic drug for cancer therapy. Anticancer Drugs 14, 91-96 (2003).

190. Gingras, D., Batist, G. \& Beliveau, R. AE-941 (neovastat): a novel multifunctional antiangiogenic compound. Expert Rev. Anticancer Ther. 1, 341-347 (2001).

191. Mao, J. W., He, X. M., Tang, H. Y. \& Wang, Y. D. Protective role of metalloproteinase inhibitor (AE-941) on ulcerative colitis in rats. World J. Gastroenterol. 18, 7063-7069 (2012)

192. Huang, T. Y. et al. Minocycline attenuates experimenta colitis in mice by blocking expression of inducible nitric oxide synthase and matrix metalloproteinases. Toxicol. Appl. Pharmacol. 237 69-82 (2009).

193. Wang, Y. D. \& Wang, W. Protective effect of ilomastat on trinitrobenzenesulfonic acid-induced ulcerative colitis in rats. World J. Gastroenterol. 14, 5683-5688 (2008)

194. Naito, Y. et al. An orally active matrix metalloproteinase inhibitor, ONO-4817, reduces dextran sulfate sodium-induced colitis in mice. Inflamm. Res. 53, 462-468 (2004).

195. Medina, C. et al. Increased activity and expression of matrix metalloproteinase-9 in a rat model of distal colitis. Am. J. Physiol. Gastrointest. Liver Physiol. 284, G116-G122 (2003)

196. Rath, T. et al. Cellular sources of MMP-7, MMP-13 and MMP-28 in ulcerative colitis. Scand. J. Gastroenterol 45, 1186-1196 (2010).

197. von Lampe, B., Barthel, B., Coupland, S. E. Riecken, E. O. \& Rosewicz, S. Differential expression of matrix metalloproteinases and their tissue inhibitors in colon mucosa of patients with inflammatory bowel disease Gut 47, 63-73 (2000).

198. Lakatos, G. et al. The impact of matrix metalloproteinases and their tissue inhibitors in inflammatory bowel diseases. Dig. Dis. 30 289-295 (2012)

199. Koelink, P. J. et al. Collagen degradation and neutrophilic infiltration: a vicious circle in inflammatory bowel disease. Gut 63, 578-587 (2014).

200. Santana, A et al Attenuation of dextran sodium sulphate induced colitis in matrix metalloproteinase-9 deficient mice. World J. Gastroenterol. 12, 6464-6472 (2006)

201. Castaneda, F. E. et al. Targeted deletion of metalloproteinase 9 attenuates experimental colitis in mice: central role of epithelial-derived MMP. Gastroenterology 129, 1991-2008 (2005). 
202. Liu, H. et al. Constitutive expression of MMP9 in intestinal epithelium worsens murine acute colitis and is associated with increased levels of proinflammatory cytokine Kc. Am. J. Physiol. Gastrointest. Liver Physiol. 304, G793-G803 (2013).

203. Ishida, K. et al. Role of chymase-dependent matrix metalloproteinase- 9 activation in mice with dextran sodium sulfate-induced colitis. J. Pharmacol. Exp. Ther. 324, 422-426 (2008).

204. Rodrigues, D. M. et al. Matrix metalloproteinase 9 contributes to gut microbe homeostasis in a model of infectious colitis. BMC Microbiol. 12, 105 (2012).

205. Garg, P. et al. Selective ablation of matrix metalloproteinase- 2 exacerbates experimental colitis: contrasting role of gelatinases in the pathogenesis of colitis. J. Immunol. 177, 4103-4112 (2006).

206. Garg, P. et al. Matrix metalloproteinase-9-mediated tissue injury overrides the protective effect of matrix metalloproteinase-2 during colitis. Am. J. Physiol. Gastrointest Liver Physiol. 296, G175-G184 (2009).

207. Wang, Y. D., Tan, X. Y. \& Zhang, K. Correlation of plasma MMP-1 and TIMP-1 levels and the colonic mucosa expressions in patients with ulcerative colitis. Mediators Inflamm. 2009, 275072 (2009).

208. Stallmach, A. et al. Comparable expression of matrix metalloproteinases 1 and 2 in pouchitis and ulcerative colitis. Gut 47, 415-422 (2000).

209. Wang, Y. D. \& Yan, P. Y. Expression of matrix metalloproteinase- 1 and tissue inhibitor of metalloproteinase- 1 in ulcerative colitis. World J. Gastroenterol. 12, 6050-6053 (2006)

210. Wang, Y. D. \& Mao, J. W. Expression of matrix metalloproteinase- 1 and tumor necrosis factor- $\alpha$ in ulcerative colitis. World J. Gastroenterol. 13 , 5926-5932 (2007).

211. Gordon, J. N. et al. Matrix metalloproteinase-3 production by gut IgG plasma cells in chronic inflammatory bowel disease. Inflamm. Bowel Dis. 14, 195-203 (2008)

212. Meijer, M. J. et al. Increased mucosal matrix metalloproteinase- $1,-2,-3$ and -9 activity in patients with inflammatory bowel disease and the relation with Crohn's disease phenotype. Dig. Liver Dis. 39, 733-739 (2007)

213. Kruidenier, L., MacDonald, T. T., Collins, J. E., Pender, S. L. \& Sanderson, I. R. Myofibroblast matrix metalloproteinases activate the neutrophil chemoattractant CXCL7 from intestinal epithelia cells. Gastroenterology 130, 127-136 (2006)

214. Kobayashi, K. et al. Therapeutic implications of the specific inhibition of causative matrix metalloproteinases in experimental colitis induced by dextran sulphate sodium. J. Pathol. 209, 376-383 (2006).

215. Koller, F. L. et al. Lack of MMP10 exacerbates experimental colitis and promotes development of inflammation-associated colonic dysplasia. Lab. Invest. 92, 1749-1759 (2012).

216. Hackam, D. J., Afrazi, A., Good, M. \& Sodhi, C. P. Innate immune signaling in the pathogenesis of necrotizing enterocolitis. Clin. Dev. Immunol. 2013 475415 (2013).

217. Pender, S. L. et al. Matrix metalloproteinases in necrotising enterocolitis. Pediatr. Res. 54, 160-164 (2003).

218. Bister, V. et al. Matrilysins-1 and -2 (MMP-7 and -26) and metalloelastase (MMP-12), unlike MMP-19, are up-regulated in necrotizing enterocolitis. J. Pediatr. Gastroenterol. Nutr. 40, 60-66 (2005).

219. Gunther, U. et al. Fibrogenesis and fibrolysis in collagenous colitis. Patterns of procollagen types I and IV, matrix-metalloproteinase-1 and -13, and TIMP-1 gene expression. Am. J. Pathol. 155, 493-503 (1999).

220. Altadill, A. et al. Comparative analysis of the expression of metalloproteases and their inhibitors in resected crohn's disease and complicated diverticular disease. Inflamm. Bowel Dis. 18 120-130 (2012).

221. Rosemar, A., Ivarsson, M. L., Borjesson, L. \& Holmdahl, L. Increased concentration of tissue degrading matrix metalloproteinases and thei inhibitor in complicated diverticular disease. Scand. J. Gastroenterol. 42, 215-220 (2007).

222. Morancho, A., Rosell, A., Garcia-Bonilla, L. \& Montaner, J. Metalloproteinase and stroke infarct size: role for anti-inflammatory treatment? Ann. NY Acad. Sci. 1207, 123-133 (2010).

223. Romi, F., Helgeland, G. \& Gilhus, N. E. Serum levels of matrix metalloproteinases: implications in clinical neurology. Eur. Neurol. 67, 121-128 (2012).
224. Seo, J. H. et al. Neurovascular matrix metalloproteinases and the blood-brain barrier. Curr. Pharm. Design 18, 3645-3648 (2012).

225. Florczak-Rzepka, M., Grond-Ginsbach, C. Montaner, J. \& Steiner, T. Matrix metalloproteinases in human spontaneous intracerebral hemorrhage: an update. Cerebrovasc. Dis. 34, 249-262 (2012).

226. Yamashita, T. \& Abe, K. Therapeutic approaches to vascular protection in ischemic stroke. Acta Med. Okayama 65, 219-223 (2011)

227. Mroczko, B., Groblewska, M. \& Barcikowska, M. The role of matrix metalloproteinases and tissue inhibitors of metalloproteinases in the pathophysiology of neurodegeneration: a literature study. J. Alzheimers Dis. 37, 273-283 (2013).

228. Elgebaly, M. M. et al. Vascular protection in diabetic stroke: role of matrix metalloprotease-dependent vascular remodeling. J. Cereb. Blood Flow Metab. 30, 1928-1938 (2010)

229. Kurzepa, J., Kurzepa, J., Golab, P., Czerska, S $\&$ Bielewicz, J. The significance of matrix metalloproteinase (MMP)-2 and MMP-9 in the ischemic stroke. Int. J. Neurosci. http://dx.doi.org 10.3109/00207454.2013.872102 (2014).

230. Chaturvedi, M \& Kaczmarek L MMP-9 inhibition: a therapeutic strategy in ischemic stroke. Mol. Neurobiol. 49, 563-573 (2014)

231. Zheng, K. et al. Matrix metalloproteinases and their tissue inhibitors in serum and cerebrospinal fluid of patients with moderate and severe traumatic brain injury. Neurol. India 61, 606-609 (2013)

232. Ulrich, N. H., Dehmel, T., Wittsack, H. J., Kieseier, B. C. \& Seitz, R. J. Peripheral blood levels of matrix metalloproteinase-9 predict lesion volume in acute stroke. Neurol. Sci. 34, 379-382 (2013).

233. Svedin, P., Hagberg, H., Savman, K., Zhu, C. $\delta$ Mallard, C. Matrix metalloproteinase-9 gene knock-out protects the immature brain after cerebral hypoxiaischemia. J. Neurosci. 27, 1511-1518 (2007).

234. Wang, X. et al. Effects of matrix metalloproteinase-9 gene knock-out on morphological and motor outcomes after traumatic brain injury. J. Neurosci. 20, 7037-7042 (2000)

235. Asahi, M. et al. Effects of matrix metalloproteinase-9 gene knock-out on the proteolysis of blood-brain barrier and white matter components after cerebral ischemia. J. Neurosci. 21, 7724-7732 (2001).

236. Gidday, J. M. et al. Leukocyte-derived matrix metalloproteinase-9 mediates blood-brain barrier breakdown and is proinflammatory after transient focal cerebral ischemia. Am. J. Physiol. Heart Circ Physiol. 289, H558-568 (2005).

237. Shichi, K. et al. Involvement of matrix metalloproteinase-mediated proteolysis of neural cell adhesion molecule in the development of cerebral ischemic neuronal damage. J. Pharmacol. Exp. Ther 338, 701-710 (2011)

238. Hu, Q. et al. Lentivirus-mediated transfer of MMP-9 shRNA provides neuroprotection following foca ischemic brain injury in rats. Brain Res. 1367 347-359 (2011).

239. Romanic, A. M., White, R. F., Arleth, A. J., Ohlstein, E. H. \& Barone, F. C. Matrix metalloproteinase expression increases after cerebral focal ischemia in rats: inhibition of matrix metalloproteinase-9 reduces infarct size. Stroke 29, 1020-1030 (1998).

240. Hu, Q. et al. Therapeutic application of gene silencing MMP-9 in a middle cerebral artery occlusion-induced focal ischemia rat model. Exp. Neurol. 216, 35-46 (2009)

241. Verslegers, M., Lemmens, K., Van Hove, I. \& Moons, L. Matrix metalloproteinase- 2 and -9 as promising benefactors in development, plasticity and repair of the nervous system. Progress Neurobiol. 105, 60-78 (2013)

242. Asahi, M., Sumii, T., Fini, M. E., Itohara, S. \& Lo, E. H. Matrix metalloproteinase 2 gene knockout has no effect on acute brain injury after focal ischemia. Neuroreport 12, 3003-3007 (2001).

243. Walker, E. J. \& Rosenberg, G. A. TIMP-3 and MMP-3 contribute to delayed inflammation and hippocampal neuronal death following global ischemia. Exp. Neurol. 216, 122-131 (2009)

244. Hadass, O. et al. Selective inhibition of matrix metalloproteinase- 9 attenuates secondary damage resulting from severe traumatic brain injury. PLOS ONE 8, e76904 (2013).

245. Jiang, J. Y. et al. MMP-9 inhibitor SB-3CT attenuates behavioral impairments and hippocampal loss after traumatic brain injury in rat. J. Neurotrauma 31 1225-1234 (2014).
246. Cui, J. et al. Inhibition of MMP-9 by a selective gelatinase inhibitor protects neurovasculature from embolic focal cerebral ischemia. Mol. Neurodegener. 7, 21 (2012)

247. Ranasinghe, H. S. et al. Inhibition of MMP-9 activity following hypoxic ischemia in the developing brain using a highly specific inhibitor. Dev. Neurosci. 34, 417-427 (2012)

248. Guo, Z. D. et al. Matrix metalloproteinase 9 inhibition reduces early brain injury in cortex after subarachnoid hemorrhage. Acta Neurochir. Suppl. 110, 81-84 (2011)

249. Burggraf, D., Trinkl, A., Dichgans, M. \& Hamann, G. F. Doxycycline inhibits MMPs via modulation of plasminogen activators in focal cerebral ischemia. Neurobiol. Dis. 25, 506-513 (2007).

250. Copin, J. C., Merlani, P., Sugawara, T., Chan, P. H. \& Gasche, Y. Delayed matrix metalloproteinase inhibition reduces intracerebral hemorrhage after embolic stroke in rats. Exp. Neurol. 213, 196-201 (2008).

251. Lee, H., Park, J. W., Kim, S. P., Lo, E. H. \& Lee, S. R. Doxycycline inhibits matrix metalloproteinase-9 and laminin degradation after transient global cerebral ischemia. Neurobiol. Dis. 34, 189-198 (2009).

252. Pires, P. W. et al. Doxycycline, a matrix metalloprotease inhibitor, reduces vascular remodelin and damage after cerebral ischemia in stroke-prone spontaneously hypertensive rats. Am. J. Physiol. Heart Circ. Physiol. 301, H87-H97 (2011).

253. Wang, Z., Xue, Y., Jiao, H., Liu, Y. \& Wang, P. Doxycycline-mediated protective effect against focal cerebral ischemia-reperfusion injury through the modulation of tight junctions and PKC $\delta$ signaling in rats. J. Mol. Neurosci. 47, 89-100 (2012).

254. Yrianheikki, J. et al. A tetracycline derivative, minocycline, reduces inflammation and protects against focal cerebral ischemia with a wide therapeutic window. Proc. Natl Acad. Sci. USA 96, 13496-13500 (1999).

255. Yrjanheikki, J., Keinanen, R., Pellikka, M., Hokfelt, T. \& Koistinaho, J. Tetracyclines inhibit microglial activation and are neuroprotective in global brain ischemia. Proc. Natl Acad. Sci. USA 95, 15769-15774 (1998)

256. Bhatt, L. K. \& Addepalli, V. Potentiation of aspirin-induced cerebroprotection by minocycline: a therapeutic approach to attenuate exacerbation of transient focal cerebral ischaemia. Diab. Vasc. Dis. Res. 9, 25-34 (2012)

257. Pfefferkorn, T. \& Rosenberg, G. A. Closure of the blood-brain barrier by matrix metalloproteinase inhibition reduces rtPA-mediated mortality in cerebral ischemia with delayed reperfusion. Stroke 34, 2025-2030 (2003).

258. Walker, E. J. \& Rosenberg, G. A. Divergent role for MMP-2 in myelin breakdown and oligodendrocyte death following transient global ischemia. J. Neurosci. Res. 88, 764-773 (2010)

259. Zhao, B. Q. et al. Role of matrix metalloproteinases in delayed cortical responses after stroke. Nature Med. 12, 441-445 (2006)

260. Liu, W., Hendren, J., Qin, X. J., Shen, J. \& Liu, K. J. Normobaric hyperoxia attenuates early blood-brain barrier disruption by inhibiting MMP-9-mediated occludin degradation in focal cerebral ischemia. J. Neurochem. 108, 811-820 (2009)

261. Rosenberg, G. A., Estrada, E. Y. \& Dencoff, J. E. Matrix metalloproteinases and TIMPs are associated with blood-brain barrier opening after reperfusion in rat brain. Stroke 29, 2189-2195 (1998).

262. Yang, Y., Estrada, E. Y., Thompson, J. F., Liu, W. \& Rosenberg, G. A. Matrix metalloproteinase-mediated disruption of tight junction proteins in cerebral vessels is reversed by synthetic matrix metalloproteinase inhibitor in focal ischemia in rat. J. Cereb. Blood Flow Metab. 27, 697-709 (2007).

263. Sood, R. R., Taheri, S., Candelario-Jalil, E. Estrada, E. Y. \& Rosenberg, G. A. Early beneficial effect of matrix metalloproteinase inhibition on blood-brain barrier permeability as measured by magnetic resonance imaging countered by impaired long-term recovery after stroke in rat brain J. Cereb. Blood Flow Metab. 28, 431-438 (2008).

264. Yang, Y et al. Increased intranuclear matrix metalloproteinase activity in neurons interferes with oxidative DNA repair in focal cerebral ischemia. J. Neurochem. 112, 134-149 (2010).

265. Amantea, D., Corasaniti, M. T., Mercuri, N. B., Bernardi, G. \& Bagetta, G. Brain regional and cellular localization of gelatinase activity in rat that have undergone transient middle cerebral artery occlusion. Neuroscience 152, 8-17 (2008) 
266. Chen, W. et al. Matrix metalloproteinases inhibition provides neuroprotection against hypoxia-ischemia in the developing brain. J. Neurochem. 111, 726-736 (2009).

267. Gu, Z. et al. S-nitrosylation of matrix metalloproteinases: signaling pathway to neuronal cell death. Science 297, 1186-1190 (2002).

268. Lee, S. R. et al. Involvement of matrix metalloproteinase in neuroblast cell migration from the subventricular zone after stroke. J. Neurosci. 26, 3491-3495 (2006).

269. Yang, Y. et al. Early inhibition of MMP activity in ischemic rat brain promotes expression of tight junction proteins and angiogenesis during recovery. J. Cereb. Blood Flow Metab. 33, 1104-1114 (2013).

270. Mishiro, K. et al. A broad-spectrum matrix metalloproteinase inhibitor prevents hemorrhagic complications induced by tissue plasminogen activator in mice. Neuroscience 205, 39-48 (2012).

271. Nagel, S. et al. Selective MMP-inhibition with Ro 28-2653 in acute experimental stroke - a magnetic resonance imaging efficacy study. Brain Res. 1368 264-270 (2011)

272. Thomsen, L. B. et al. Brain delivery systems via mechanism independent of receptor-mediated endocytosis and adsorptive-mediated endocytosis. Curr. Pharm. Biotechnol. 13, 2349-2354 (2012).

273. Guo, L., Ren, J. \& Jiang, X. Perspectives on brain-targeting drug delivery systems. Curr. Pharm. Biotechnol. 13, 2310-2318 (2012).

274. Tang, Y. et al. MT1-MMP-dependent control of skeletal stem cell commitment via a beta1-integrin/ YAP/TAZ signaling axis. Dev. Cell 25, 402-416 (2013).

275. Dufour, A. \& Overall, C. M. Missing the target: matrix metalloproteinase antitargets in inflammation and cancer. Trends Pharmacol. Sci. 34, 233-242 (2013).

276. Ghosh, D. et al. Paneth cell trypsin is the processing enzyme for human defensin-5. Nature Immunol. 3, 583-590 (2002).

277. Lindsey, M. L. \& Zamilpa, R. Temporal and spatial expression of matrix metalloproteinases and tissue inhibitors of metalloproteinases following myocardial infarction. Cardiovascular Ther. 30, 31-41 (2012).

278. Scherer, R. L., McIntyre, J. O. \& Matrisian, L. M. Imaging matrix metalloproteinases in cancer Cancer Metastasis Rev. 27, 679-690 (2008)

279. Yang, K. et al. Visualization of protease activity in vivo using an activatable photo-acoustic imaging probe based on CuS nanoparticles. Theranostics 4 134-141 (2014).
280. Waschkau, B., Faust, A., Schafers, M. \& Bremer, C. Performance of a new fluorescence-labeled MMP inhibitor to image tumor MMP activity in vivo in comparison to an MMP-activatable probe. Contrast Media Mol. Imag. 8, 1-11 (2013).

281. Matusiak, N. et al. Probes for non-invasive matrix metalloproteinase-targeted imaging with PET and SPECT. Curr. Pharm. Design 19, 4647-4672 (2013).

282. Fingleton, B. Matrix metalloproteinases as valid clinical targets. Curr. Pharm. Design 13, 333-346 (2007).

283. Roy, R., Yang, J. \& Moses, M. A. Matrix metalloproteinases as novel biomarkers and potential therapeutic targets in human cancer. J. Clin. Oncol. 27, 5287-5297 (2009)

284. Hayden, D. M., Forsyth, C. \& Keshavarzian, A. The role of matrix metalloproteinases in intestinal epithelial wound healing during normal and inflammatory states. J. Surg. Res. 168, 315-324 (2011).

285. Tugwood, J. D. et al. Fibrodysplasia induced in dog skin by a matrix metalloproteinase (MMP) inhibitor a mechanistic analysis. Toxicol. Sci. 127, 236-245 (2012)

286. Moake, J. L. von Willebrand factor, ADAMTS-13, and thrombotic thrombocytopenic purpura. Seminars Hematol. 41, 4-14 (2004).

287. Sela-Passwell, N., Trahtenherts, A., Kruger, A $\&$ Sagi, I. New opportunities in drug design of metalloproteinase inhibitors: combination between structure-function experimental approaches and systems biology. Expert Opin. Drug Discov. 6 527-542 (2011).

288. Devel, L. et al. Third generation of matrix metalloprotease inhibitors: gain in selectivity by targeting the depth of the $\mathrm{S} 1$ ' cavity. Biochimie 92, 1501-1508 (2010)

289. Kothapalli, R. et al. Cheminformatics-based drug design approach for identification of inhibitors targeting the characteristic residues of MMP-13 hemopexin domain. PLOS ONE 5, e12494 (2010).

290. Hu, J. et al. Inhibition of lethal endotoxin shock with an L-pyridylalanine containing metalloproteinase inhibitor selected by high-throughput screening of a new peptide library. Comb. Chem. High Throughput Screen. 9, 599-611 (2006).

291. Mannello, F. \& Medda, V. Nuclear localization of matrix metalloproteinases. Progress Histochem. Cytochem. 47, 27-58 (2012)

292. Cauwe, B. \& Opdenakker, G. Intracellular substrate cleavage: a novel dimension in the biochemistry, biology and pathology of matrix metalloproteinases. Crit. Rev. Biochem. Mol. Biol. 45, 351-423 (2010)
293. Soslau, G. et al. Intracellular matrix metalloproteinase-2 (MMP-2) regulates human platelet activation via hydrolysis of talin. Thromb. Haemostasis 111, 140-153 (2014).

294. Solli, A. I., Fadnes, B., Winberg, J. O., Uhlin-Hansen, L. $\&$ Hadler-Olsen, E. Tissue- and cell-specific co-localization of intracellular gelatinolytic activity and matrix metalloproteinase 2. J. Histochem. Cytochem. 61, 444-461 (2013)

295. Sawicki, G. Intracellular regulation of matrix metalloproteinase-2 activity: new strategies in treatment and protection of heart subjected to oxidative stress. Scientifica 2013, 130451 (2013)

296. Zuo, X., Pan, W., Feng, T., Shi, X. \& Dai, J. Matrix metalloproteinase 3 promotes cellular anti-dengue virus response via interaction with transcription factor NFKB in cell nucleus. PLOS ONE 9, e84748 (2014).

297. Marchant, D. J. et al. A new transcriptional role for matrix metalloproteinase-12 in antiviral immunity. Nature Med. 20, 493-502 (2014).

298. Muyldermans, S. Nanobodies: natural single-domain antibodies. Annu. Rev. Biochem. 82, 775-797 (2013).

299. Holmbeck, K. et al. MT1-MMP-deficient mice develop dwarfism, osteopenia, arthritis, and connective tissue disease due to inadequate collagen turnover. Cell 99 81-92 (1999)

300. Zhou, Z. et al. Impaired endochondral ossification and angiogenesis in mice deficient in membrane-type matrix metalloproteinase I. Proc. Natl Acad. Sci. USA 97, 4052-4057 (2000).

301. Kim, J. W. et al. MMP-20 mutation in autosomal recessive pigmented hypomaturation amelogenesis imperfecta. J. Med. Genet. 42, 271-275 (2005).

302. Papagerakis, P. et al. Premature stop codon in MMP20 causing amelogenesis imperfecta. J. Dental Res. 87 56-59 (2008)

303. Iwasaki, M. et al. Anti-invasive effect of MMI-166 a new selective matrix metalloproteinase inhibitor in cervical carcinoma cell lines. Gynecol. Oncol. 85, 103-107 (2002)

\section{Acknowledgements}

This work was supported by FWO Vlaanderen, Belgium and by the IAP initiative of Belgian Society Policy. The authors thank A. Bredan for editing the manuscript.

Competing interests statement

The authors declare no competing interests.

SUPPLEMENTARY INFORMATION

See online article: $\underline{\mathrm{S}}$ (table)

ALL LINKS ARE ACTIVE IN THE ONLINE PDF 